\title{
Protection heterogeneity in a harmonized European patent system
}

\author{
Raphael Zingg ${ }^{1,2} \cdot$ Erasmus Elsner $^{2}$
}

Published online: 12 May 2020

(c) The Author(s) 2020

\begin{abstract}
This study proposes a divergent expectation model for patent infringement disputes, where both litigation and settlement are driven by patent quality. Under the model, patent quality depends on both broadness and definiteness of the patent. The model predicts that technologies where the definiteness attribute can be estimated with high accuracy will have higher settlement rates. At trial, it is rather the assessment of the patent quality by the judge which decides the outcome. In its empirical section, the paper evaluates over a thousand hand-collected and hand-coded patent infringement and counterclaim decisions rendered by courts in the three largest patent granting European countriesGermany, France and the United Kingdom. The paper utilizes empirical methods to investigate whether the characteristics of the patents or the country of litigation predict the outcome of litigation. Examination of the patent characteristics is guided by the factors of our model, in that the patent quality, and underlying technology and industry are tested. The findings provide evidence of the continuing heterogeneity of the patent systems in Europe, despite the harmonization efforts. Demonstrated was the lack of importance of the characteristics of the litigated patent; rather, it was the forum to which the case was brought that was decisive. At the dawn of the Unified Patent Court, our study provides for a window into the extent of heterogeneity still prevailing and a starting point for monitoring the further development of European patent harmonization.
\end{abstract}

Keywords Patent litigation · Patent systems · Harmonization · National courts · Unified patent court

JEL Classification D84 $\cdot \mathrm{K} 11 \cdot \mathrm{K} 41 \cdot 034$

\begin{abstract}
We are grateful to Stefan Bechtold, Heiko Karle, David Schwartz, Wolfgang Kerber, Ludvig Wier, two anonymous reviewers, and the participants of the Third Roundtable on Empirical Methods in Intellectual Property at the USPTO, the 34th Annual Meeting of European Association of Law and Economics, the 112th Annual Meeting of the Association of American Law Schools, the Second Munich Summer Institute, the Brownbag Seminar of the Max Planck Institute for Innovation and Competition and the Internal Seminar in Law \& Economics at ETH Zurich for comments and suggestions. The paper was granted the Göran Skogh Award 2017 by the European Association of Law and Economics and the Forum for Law and Economics.
\end{abstract}

Extended author information available on the last page of the article 


\section{Introduction}

With the goal of fostering innovation in Europe, central and declared policy has aimed for the harmonization of patent systems over the last fifty years. Through the harmonization of the laws governing patent rights, the development of a single and unified market for innovation and technology is pursued. European countries have moved towards homogeneity by adjusting their national regimes under the roof of the Strasbourg Convention of 1963 and the European Patent Convention in 1973 (EPC). ${ }^{1}$ Creating common standards across the internal market seeks to establish a level playing field. ${ }^{2}$ A harmonized set of rules allow for an autonomous system of patent protection, hinging on substantive patentability requirements and the establishment of European patents. This effort towards harmonization, however, is undermined if the practices of the national courts systematically diverge. ${ }^{3}$ Anecdotal evidence such as the Epilady litigation has raised doubt upon the success of said harmonization. Claiming that the company Remington had violated its patent through a device with the same function but different mechanism, Epilady launched infringement proceedings in several European countries. Whereas the courts in Belgium, Germany, Italy and the Netherlands ruled in favor of the infringement, judges in Austria, France and the United Kingdom came to the opposite conclusion. ${ }^{4}$ Disconcertingly, the courts had to interpret the same patent, operate under very similar facts and utilized a common standard of interpretation; yet they came to polar decisions. ${ }^{5}$ Even under harmonized laws, national divergent interpretations remain possible. ${ }^{6}$

The European Patent Office (EPO) offers a centralized examination procedure for the nowadays 38 member states of the European Patent Convention. Once granted, a European patent however requires to be validated at national level and moves in a country-by-country enforcement regime. Despite the harmonization efforts, enforcing a patent infringement lawsuit in Europe still occurs on a per-country basis. That is, proceedings in a national court can only be brought in respect to damages that

\footnotetext{
1 Convention on the Unification of Certain Points of Substantive Law on Patents for Invention, signed November 27, 1963 and Convention on the Grant of European Patents of 5 October 1973. For a historical account, see Yarsky (2017) and Murashige (1994) naming it '[a] giant step toward harmonization'.

2 See Alesina et al. (2005) discussing the trade-off between the benefits of centralization (economies of scale, positive externalities) and its costs (heterogeneity of preferences in a large union) and more generally see Duffy (2002) and Nard and Duffy (2007) for the benefits of harmonization. It has been estimated that bilateral trade of services within the European Union could be boosted by $30-60 \%$ by a uniform regulatory system, see Kox et al. (2004).

3 Laddie (2009) on how the benefits secured by the creation of a central granting authority are undermined if the granted patents vary in their effects in the different Member States of the EPC; this phenomena may be explained by the fact that Member States face conflicting incentives: whereas there is a need for harmonization for the regulation of transnational trading flows and relationships, the costs of harmonization-learning, adapting and risk of failure-may be considerable and are coupled with the loss of the advantages resulting from territoriality, see Larouche (2013, p. 282).

4 A detailed summary of the case can be found with Mejer and van Pottelsberghe de la Potterie (2009).

5 See Hatter (1995, p. 486) for an analysis of the lawsuits and the underlying doctrine of equivalents.

6 See Bender (2000) on the inherent conflict between national patent law and the European Patent Convention and Di Cataldo (2002) characterizing the situation as 'deadlock'.
} 
occurred within that forum. ${ }^{7}$ Previous practices by courts-especially in the Netherlands - to grant cross-border injunctions have been struck down or largely limited by the European Court of Justice. ${ }^{8}$ Similarly, issues of patent validity, with the exception of the opposition before the EPO, are to be determined under the respective national law. Challenging the validity of a European patent in one country thus has effect for this specific national part of the European patent only. Beyond the costs of validation of patents, ${ }^{9}$ the current system is characterized by the legal complexity for litigating parties to enforce their rights at the country level. In the event of a dispute, the enforcement of patents will be subject to a highly variable institutional set of enforcement rules, whose harmonization is far from complete. At the institutional court level, the dual German enforcement system-so-called bifurcationdissociates infringement and validity claims which are heard by separate courts; in other countries both issues are tried by the same court. The cost structure for enforcing a patent in the United Kingdom (UK) is substantially higher compared to other countries. ${ }^{10}$ Resultant of the difference in experience of judgment-making in patent cases, quality and speed of the courts diverge. A range of procedural provisions such as provisional measures, language of proceedings or rulings on evidence and the onus of proof characterize the individual states. ${ }^{11}$ In terms of damages, the EU Enforcement Directive has harmonized the calculation methods, but variances in the amount of the level of damages across countries exists. ${ }^{12}$

Important differences between European countries in terms of outcomes, share of appealed cases and characteristics of litigants and litigated patents have been revealed in the last years. The first large-scale empirical study of patent litigation was led by Graham and Van Zeebroeck (2014). Relying on a database of nearly 9000 patent lawsuits in the seven largest countries in the European Union, the authors showed that the incidence and base of judicial outcomes widely varied by country and by patented technology. A second empirical project by Cremers et al. (2016) furnished an exhaustive picture of the litigation landscape in Germany, France, the Netherlands and the United Kingdom by evaluating a dataset of hand-coded suits

\footnotetext{
7 The so-called 'Shevill' doctrine, see ECJ, Shevill (C-98/93); see also the Brussels Regime with its EU Regulation 44/2001 replaced by EU Regulation 1215/2012.

${ }^{8}$ In GAT v Luk (C-4/03), July 13, 2006, the European Court of Justice (ECJ) held that national courts have no jurisdiction over the infringement of foreign parts of an European patent when the validity of latter patent is challenged. In Roche v Primus (C-539/03), July 13, 2006, the ECJ decided that claims to infringement of a set of national parts of a European patent have to be so closely connected that is is 'expedient' to hear and determine them together to avoid the risk of irreconcilable judgments.

9 The costs of validation for European patents are at least five times more expensive than their US counterparts, see Mejer and van Pottelsberghe de la Potterie (2009).

${ }^{10}$ With costs in the UK in an aggregate of between $£ 1$ million and $£ 6$ million, see Helmers and McDonagh (2013). These figures are to be compared to costs of EUR 50,000 to 200,000 in France and of EUR 25,000 to EUR 91,456 for the court fees and of EUR 40,000 to EUR 100,000 for attorney fees in Germany, see Cremers et al. (2016).

${ }^{11}$ See the detailed analysis by Luginbuehl (2011, p. 64).

12 See Graham and Van Zeebroeck (2014, p. 667) estimating the awarded damages in Belgium, France and Italy as low, in Germany and the Netherlands as average, and in the UK as high; see EU Directive 2004/48/EC and it's Article 13 paragraph 1 that obliged France to award the infringer's profits as a damage (Luginbuehl (2011, p. 70)).
} 
filed between 2000 and 2008. They found substantial differences across countries in terms of case loads and outcomes, and characteristics of both litigants and patents. In addition, several recent studies focused on patent enforcement in one particular jurisdiction, presenting evidence of a European landscape characterized by fragmentation and uncertainty for innovators, patent holders and their competitors. ${ }^{13,14}$

In examining the behavior of courts of different jurisdictions, case comparison is complicated by the differentiating subject-matter. Forum shopping enables entities to conduct a gamification of the system by acknowledging the odds of winning and competence of different courts. As such, simply contrasting win rates between two jurisdictions might not be sufficient. Nature of the cases tried by courts differ. Under a harmonized system, systematic differences in the likelihood of patents to be enforced with success should correspond to those characteristics. Put otherwise, patents with similar characteristics and similar strength should, in the limit, reach similar outcomes. By contrast, if the differences rely solely on the country of jurisdiction-and not on the characteristics of the underlying invention-the harmonization policy goal is not being achieved. ${ }^{15}$ This would imply that traditions existing before the entry into force of the European Patent Convention have survived to some extent or that current policies diverge. ${ }^{16}$

To study the extent of harmonization in Europe, this paper investigates the characteristics of patent disputes brought before the courts. We introduce a model that enables us to study patent litigation across countries, despite the selection effect. We propose a model where both litigation and settlement are driven by patent quality. We use patent quality as a novel and broadly laid out term that encapsulates both legal validity and economic value. Put differently, we assume that high quality patents are those with strong legal validity and/or high economic value. We assume that patent quality depends on both broadness and definiteness of the patent, whereby broadness relates to the scope of protection as defined by the patent's claims and definiteness relates to the precision of these claims. Notably, patent definiteness is not a wholly separate factor to patent broadness, but rather the unobservable portion of patent broadness that sets out the borders of the patent's claims. While we

\footnotetext{
13 For the UK, Helmers and McDonagh (2013) built a dataset containing the complete set of patent litigation filed at the courts in England and Wales from 2000 to 2008, showing the distribution by technology and by sector of the litigating companies. In Germany, Cremers (2004) documented the determinants of patent infringement suits from 1993 to 1995 before the three primary infringement courts. Last, in France, Véron (2010) evaluated the decisions of the Tribunal de Grande Instance de Paris and subsequent appeals between 2000 and 2009.

14 Helmers and McDonagh (2013).

15 Hatter (1995) and Parker (2012) arguing that '[i]n actuality, the national courts of Europe have construed patents differently despite applying the so-called uniform requirements of the EPC'.

16 Illustratively, at the time before the EPC, to determine the extend of protection of a patent in infringement claims, certain countries such as the UK were applying 'peripheral claiming', with claims defining both the invention and limiting it ('what is not claimed is disclaimed'). Contrastingly, in Germany and the Netherlands, 'peripheral claiming' stated that the claims defined the invention only, being the starting point of the scope of protection. With the passage of the EPC, a 'position between [the] extremes' was adopted. As such, article 69 UPC defines a position striving a balance between protection for the patentee (reflecting the German and Dutch approach) and legal certainty for third parties (reflecting the UK approach).
} 
assume that patent broadness is measurable and certain, the patent definiteness is the unobservable and uncertain portion of the claims. In our model, patent holders and patent infringers decide before proceeding to court whether to settle or litigate based on differences in the perception of the patent's quality, i.e. based on relative patent quality assessments. We assume that technology-specific differences in patent definiteness exist, leading to different settlement and litigation rates across technologies. Each agent makes his or her own estimation of the patent quality, whereby the patent's definiteness is the factor which introduces heterogeneity in their estimation. If there is sufficient agreement, a settlement will be reached, otherwise the parties will proceed to trial. At trial, the divergent expectations of the parties are no longer material, it is rather the assessment of the absolute patent quality by the judge, i.e. the composite of both patent broadness and definiteness, which decides the outcome of the case. Notably, unlike the Priest and Klein (1984) model, we do not assume that either plaintiff or defendant is forming their respective expectation with respect to a common judicial standard of fault. This can be rationalized, as our institutional setting is the existing system of heterogeneous European patent courts, whereby patents can be litigated in multiple courts and held to different judicial standards. A limitation of our model is that factors such as misinterpretation or misinformation on the law or on case facts can be decisive in patent litigation. To overcome Priest and Klein (1984), we must assume that the error term, which results from noisy signals, is captured in our model by the patent definiteness factor. All information is captured by one quality expectation factor, which encapsulates the full information set available to parties. The model predicts that technologies where the patent definiteness attribute can be estimated with high accuracy will have higher settlement rates. Furthermore, according to the model, the absolute patent quality will be determinative of case outcome only at the litigation stage. Therefore, in contrast to Priest and Klein (1984), the model predicts that patent litigation cases where high quality patents are under dispute will have a higher probability of success and, thus, we expect to find higher win rates in our empirical dataset.

In a perfect natural experiment, the study would focus on a large number of identical patent cases, litigated by the same patent holder and decided at the same moment in time in several jurisdictions, holding all other factors, such as legal expenses or personal characteristics of judges, constant. In the absence of such a stylized setting, running laboratory experiments where judges from different jurisdictions would decide on fictitious patent cases involving different technologies and industries would also allow us to investigate causal effects more directly. In contrast, empirical studies of patent litigation data, like the one presented within this paper, are always subject to considerable limitations. To address some of these concerns, our empirical analysis is guided by our theoretical model. This model suggests that the litigation parties' divergent expectations of patent quality, broadness and definiteness, determine the population of cases heard in court. Within this initial selection, patent litigants do not form their expectations with respect to a common judicial standard of fault, as suggested by Priest and Klein (1984), but rather strategically select into different forums. The model contends that both patent case characteristics and heterogeneous judicial standards drive selection and case outcomes. Thus, the model makes patent case specific assumptions, which are subject to a number of limitations 
and may not be generalizable to other domains of the law. However, under this set of stark assumptions, we are able to draw empirical inferences at the patent litigation outcome level, in particular regarding differences across countries, technologies and industries.

The paper utilizes empirical methods to investigate whether the characteristics of the patents or the country of litigation predict the outcome of litigation. Examination of the patent characteristics is conducted in line with our model, in that the patent quality, and underlying technology and industry are tested. After detailing our model in the theory section (Sect. 2), we formulate our hypotheses (Sect. 3). We then describe the build-up of the data and its coding (Sects. 4 and 5). Descriptive and empirical results (Sects. 6 and 7) are followed by the discussion and conclusion (Sects. 8 and 9).

\section{Theory}

\subsection{Litigated patents: the tip of the iceberg}

Most patents have little monetary value ${ }^{17}$ and, therefore, expire uninfringed. ${ }^{18}$ Patent litigation data can always only be a subsample of both patent disputes and the entire patent universe. It is subject to a strong selection bias. Early law and economics scholars, in particular Priest and Klein (1984) with their seminal paper, have suggested that the cases which are litigated are the hardest ones, namely those with a 50\% chance of winning and losing. The Priest-Klein hypothesis has since been extended and/or rejected by numerous authors. ${ }^{19}$ As a result of this strong selection bias, it is suggested that no inferences can be made about legal standards from plaintiff trial win rates. We introduce a divergent expectation model for patent infringement disputes which uses building blocks of the Priest-Klein theorem and integrates these into a subjective expected utility model. We build our model in three steps: Firstly, we model the patent holder's trade-off between settlement and trial in an expected utility setting; secondly we introduce a divergent expectations framework; and lastly, we dive deeper into the dimensions of patent quality. Under our model, and in contrast to Priest-Klein, the cases at trial do not necessarily have a $50 \%$ chance of winning, but because of divergent expectations of the parties, a population of patent cases of different quality will end before the courts, and the latter quality will be determinative of the final outcome by the judge. The contribution of this model is twofold: firstly, it proposes an incremental additional to the divergent expectation model, which, secondly, motivates our factors in the empirical

\footnotetext{
17 Moore (2005) and Lemley (2001) both finding that the majority of patents lapse because of a failure of the patent holders to pay the renewal fee, indicating that there is no economic value to the protection.

18 See Lemley (2001) estimating that of about two million US patents in force, only about 2000 different patents are subject to court disputes and, of that, about 100 cases per year make it to trial.

19 Clermont (2009), Clermont and Eisenberg (2002) and Kessler et al. (1996).
} 
specification. As such, it adds a theoretical foundation to factors commonly used in the empirical patent literature.

\subsection{A microeconomic model of patent disputes}

Patent holders whose patents are infringed have a discrete choice between settling or litigating such claims. Rubinfeld and Scotchmer (1993) have modeled success and defeat in litigation as two mutually exclusive states of the world in an expected utility setting. Building on this framework, we represent the patent holder's choice set in patent infringement cases as a function of patent broadness and patent definiteness-with the technology-specific factor determining the relative weights. We define broadness as the scope of coverage of a patent and definiteness as the precision of the claim's specifications. The definiteness defines the ease with which protection in a technology field can be substantiated (e.g. through the proof of exact chemical compositions for drug patents vs. the often rather vague description of functional properties for mechanical patents).

Our model assumes that defendant and plaintiff are facing two discrete decision points that delineate two discrete stages respectively. The decision to litigate or not defines a pre-litigation stage and the decision to have the filed case adjudicated by a judge delineates a post-filing stage. In each stage, the parties can exchange settlement offers and counteroffers. We thus refer to anything occurring before a judicial decision is rendered, i.e. both the pre-litigation and post-filing stages, as the settlement stage.

The starting point of our model is the occurrence of a patent infringement dispute. At the principal node, the patent holder can decide whether to settle or litigate his respective patent claim. Through a settlement, he can avert the ambiguity of a judicial decision, since he obtains certainty over the payoff at settlement-not leaving it to an exogenous decision body. We assume that the decision agent deploys backward induction across the entire decision tree depicted in Fig. 1. This means that in our model the uncertainty of trial is carried forward all the way to the initial occurrence of the patent dispute. Therefore, the settlement decision becomes a function of the uncertain trial outcome as set out below.

We first assume that the patent holder will litigate with probability $p_{S}(\theta)$ and settle with probability $1-p_{S}(\theta)$. If he decides to litigate, he enters the "litigation lottery", where he can either win or lose. We further assume that each patent is endowed with a patent quality $\theta$, which determines both the success probability in a patent infringement trial, denoted as $p_{L}(\theta)$, and the probability of an adverse outcome, i.e. the probability that the claim is not upheld at trial, denoted by $1-p_{L}(\theta)$. Since the patent holder makes his decision by backward induction, we assume that the success probability at trial is determinative of the patent holder's initial settlement choice. ${ }^{20}$

\footnotetext{
${ }^{20}$ A microfoundation concerning these assumptions can be derived inspired by Priest and Klein (1984), but this goes beyond the scope of this paper.
} 
We can, therefore, model the trade-off between settlement and trial using a von Neumann-Morgenstern expected utility framework. The patent holder's utility function is, thus, given by:

$$
U^{\theta}(S, L)=\left(1-p_{S}(\theta)\right) u\left(S-c_{S}\right)+p_{S}(\theta) u\left(L-c_{L}\right)
$$

Figure 2 depicts the claimant's indifference curve: the vertical axis, labeled $S$, represents the patent holder's expected payoff upon settlement, whereas the horizontal axis, labeled $L$, represents his expected payoff upon litigation, with the latter being the weighted sum of the win/lose state payoff. The costs associated with negotiating the settlement are denoted as $c_{S}$, while the costs of going to trial are denoted as $c_{L}$. The settlement and litigation payoff, $S$ and $L$, respectively, must exceed $c_{S}$ and $c_{L}$, respectively, for there to be some utility for the agent $u(\cdot)>0$. We further assume that the costs of going to trial exceed those of settlement, $c_{L}>c_{S}$. The indifference curves $I_{n}$ further to the northeast represent greater expected utility and are, thus, preferred by the patent holder, i.e. $u\left(I_{3}\right)>u\left(I_{2}\right)>u\left(I_{1}\right)$.

The slope of the patent holder's indifference curve reflects the patent quality and, thus, the probability of winning a potential infringement suit $p_{L}(\theta)$. The slope is the marginal rate of substitution:

$$
M R S=-\frac{p_{S}(\theta)}{\left(1-p_{S}(\theta)\right)} \frac{u^{\prime}(S)}{u^{\prime}(L)}
$$

Therefore, the lower the patent quality, $\theta$, the flatter the patent holder's indifference curve and the larger the patent holder's relative preference for the settlement option, since for a given settlement amount, the holder of the lower quality patent requires more litigation payoff units to render him indifferent.

\subsubsection{Divergent expectations}

Both plaintiff and defendant hold different subjective expectations of the success probability at trial $p_{L}(\theta)$. In a simplified discrete setup, patents can be classified by agents as either "high" quality patents, $H$, or "low" quality patents, $L$, so that $\theta \in\{L, H\}$ at this stage. If no settlement is agreed, the patent quality will be assessed by the judge, resulting in the assignment of a "judicial" patent quality, $J$, which then determines the success probability at trial and defines the agents expected utility function at trial. Negotiation occurs in a bargaining zone, denoted by $Z$, determined by (i) the patent holder's estimation of $p_{L}(\theta)_{H}$, (ii) the patent infringer's estimation of $p_{L}(\theta)_{I}{ }^{21}$ and (iii) a range of expected litigation outcomes between $L_{\min }$ and $L_{\max }{ }^{22}$

Figure 3 illustrates a scenario where the patent holder perceives the patent to be of low quality and, therefore, as having relatively low success probability in

\footnotetext{
21 This can be plotted as a second, quasi indifference curve of the patent holder. It can also be thought of as the patent infringer's subjective assessment of what the patent holder's "fair" indifference curve should look like given his estimation of the success probability.

22 Whereby $L_{\min }=\min \left(L_{\text {patent holder }}, L_{\text {patent infringer }}\right)$ and $L_{\max }=\max \left(L_{\text {patent holder }}, L_{\text {patent infringer }}\right)$.
} 


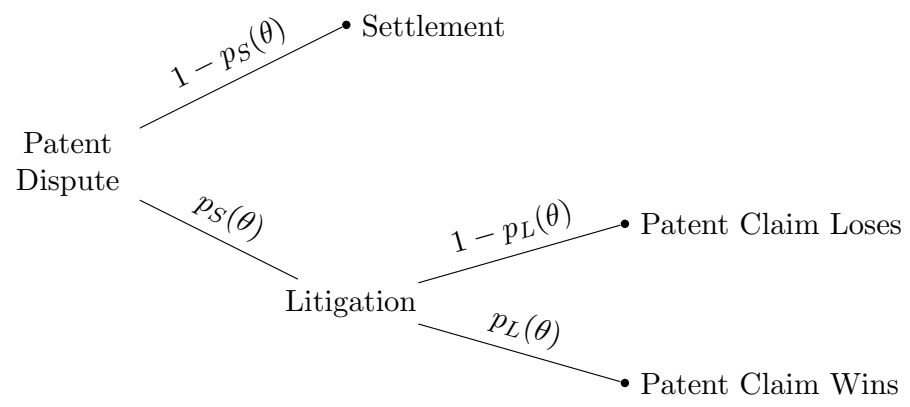

Fig. 1 Litigation versus settlement decision tree

adjudication, resulting in a relatively flat indifference curve $I_{l}$. On the other hand, the patent infringer's assessment of the patent is that it is a patent of high quality, leading to a steep settlement curve $I_{h}$. While only formed at the trial stage, $I_{j}$ denotes the indifference curve using the judicial success probability. In this set-up, it would be pareto-efficient for the patent holder and the patent infringer to reach a settlement at all litigation payoff levels, $L_{n}$. This is because a bargaining zone exists in the north-east and the south-west of the patent holder and the patent infringer, respectively, i.e. in the utility-enhancing zone (represented by the gray area in Fig. 3).

In reality, parties can settle at any stage of litigation. In our two-stage model, the settlement stage captures all bargaining occurring before a court decision is rendered by the judge. It models divergent expectations as a static endowment, where the parties do not update their beliefs with additional information being revealed during the trial. In patent disputes, however, the appointment of external experts and the questioning of witnesses by the court are typical steps that reduce information asymmetry and encourage settlements (Cremers and Schliessler 2015). The exchange of information between parties, whether voluntary or involuntary, increases the likelihood that parties reach settlements (Cooter and Ulen 2016). In our two-stage model, all information is already captured by one quality expectation factor, which encapsulates the full information set available to parties before and during trial, up to the judicial decision.

\subsubsection{Patent quality parameters}

Shifting from a discrete setup to a continuous setup, where patent quality can not only take two discrete states to $\theta \in\{\mathbb{N}\}$, we propose that patent quality should be modeled as a function of the patent's broadness, denoted as $B$, and the patent's definiteness, denoted as $D$, with the technology-specific factor, denoted as $\alpha^{j}$, determining the relative weights:

$$
\theta(B, D)=B^{\left(1-\alpha^{j}\right)} D^{\alpha^{j}}
$$

Figure 4 represents $\theta(B, D)=\bar{B}^{\left(1-\alpha^{j}\right)} D^{\alpha^{j}}$, i.e. the patent quality as a function of the patent's definiteness, $D$, with the patent's broadness held constant at different initial endowment levels. The technology-specific factor, $\alpha^{j}$, determines whether 
Fig. 2 Litigation versus settlement indifference curves

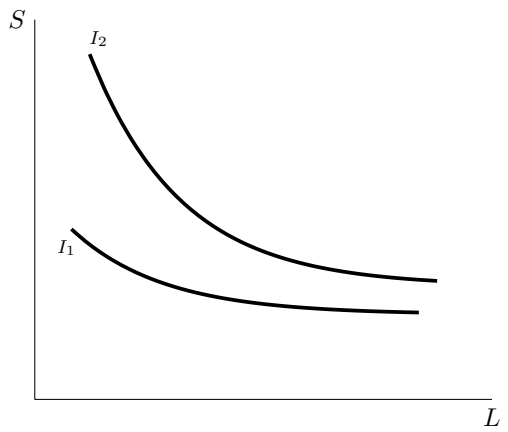

patent broadness or definiteness has more influence on patent quality and adjudication success probability. To illustrate this by analogy, patent disputes can be compared to boundary disputes in land law-with the land owner and trespasser being the equivalent to the patent holder and infringer, respectively. Patent broadness can in this analogy be thought of as the size of the land protected, while patent definiteness is the equivalent of the land's fencing or trespassing detection system. The larger the size of the land, the higher the likelihood of trespassing and the easier it is for the land owner to prove in court that trespassing has occurred, the smaller the land the more important his fencing/detection systems and the evidential threshold established by courts become.

For the purpose of our model, we further assume that patent broadness and the technology factor are observable exogenous variables and that differences in the parties' estimation of patent quality $\theta$ are solely due to patent definiteness. We assume that the accuracy of estimating the patent's true level of legal protectability, i.e. it's definiteness is technology-specific and that the standard error of estimate of the patent's definiteness can be denoted as:

$$
\sigma_{e s t}^{j}=\sqrt{\frac{\sum_{k=1}^{N_{j}}\left(D_{k}^{j}-\bar{D}^{j}\right)^{2}}{N_{j}}}
$$

These differences in the standard errors of estimates across technologies lead to different respective settlement rates. Put formally, if two technologies (A and B) exist with agents having more trouble to ascertain the boundaries of a patent in technology A than B (due to lower prediction accuracy of the patent definiteness attribute), then the initial bargaining zone is larger for this technology and the likelihood of reaching a settlement decreases.

$$
\sigma_{e s t}^{A}>\sigma_{e s t}^{B} \Rightarrow Z^{A}>Z^{B}
$$

Thus, we summarize our propositions as follows.

Proposition 1 The patent quality is a function of the patent's definiteness and broadness with the technology-specific factor as a scaling factor. 
Fig. 3 Patent infringement bargaining area

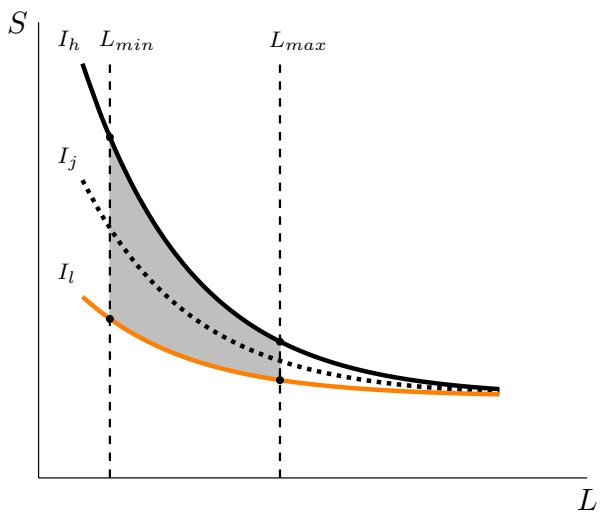

Proposition 2 Only patent disputes where it is difficult for the parties to reach agreement over patent quality (and, by extension, on the success chances at trial) defined with regard to patent definiteness will proceed to trial. Where the parties can agree on the merits of the case, irrespective of whether this entails a high or a low absolute success probability, settlement will be preferred. Thus, it is only relative success probability that determines the settlement versus litigate decision, i.e. the estimation of the success probability of the patent holder versus that of the patent infringer.

Proposition 3 If no settlement is reached, the divergent expectations of the success probability are no longer determinative of the final outcome. Rather, the key factor is the judge's assessment of patent quality and, thereby, of the adjudication success probability $p(\theta)$. It is, thus, the "absolute" quality of $p_{L}(\theta)$ that matters at the adjudication stage.

Given that the selection of cases proceeding to adjudication is made on relative patent quality, this does not tell us anything about absolute case quality and success likelihood at trial. Since patent quality, as determined by the judge, depends on patent broadness, definiteness and the technology factor, the litigation sample does not allow us to make inferences as to the population of contiguous cases. In other words, heterogeneity in case outcomes among technologies would be in line with our model's predictions, as success probability at trial depends on a host of factors in patent disputes. ${ }^{23}$

${ }^{23}$ See the "Appendix" for the relation of our model with the Priest-Klein hypothesis. 
Fig. 4 Patent quality function

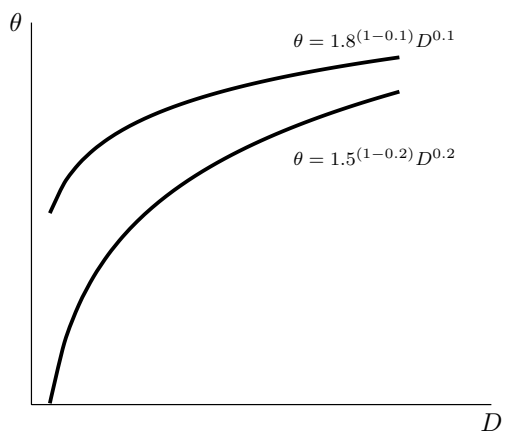

\section{Hypotheses}

We formulate the following hypotheses flowing from our microeconomic model. We predict that the outcome of court decisions over patents is predicted by the quality and, therefore, of the technology and industry of the patent at stake.

Hypothesis 1 The quality of the litigated patent is directional for the outcome of patent litigation.

Explanation. Hypothesis 1 follows directly from Proposition 3. In the absence of settlement, the patent quality will be determined by the judge, resulting in the assignment of a 'judicial' patent quality which determines the success probability at trial. The higher the quality of a patent, the more likely it is to win. In a completely harmonized patent system, the 'judicial standard' would be fully uniform across jurisdictions and judges. This would mean that given a specific patent quality level, the judgment on the case's merits should be the same. As we are trying to identify country-level differences in judicial behavior, we formulate the second hypothesis as follows.

Hypothesis 2 The technology and industry of the litigated patent is directional for the outcome of patent litigation.

Explanation. Our model predicts that the success probability at trial depends on patent quality (see Proposition 3), a function of the patent's definiteness and broadness with the technology-specific factor determining the relative weights (see Proposition 1), which imply variations in patent quality across technologies and industries. It should be noted that technology is already endogenous to case quality in our microeconomic model. In our empirical identification strategy, however, we have chosen to use technology and industry as separate factors, instead of treating them endogenous to patent quality. 


\section{Data}

We have compiled a novel dataset comprising 930 individual patent litigation infringement and counterclaim cases rendered between 2008 and 2012 across Germany, France and the United Kingdom. The 930 cases represented a total of 1402 individual court decisions. We explicitly excluded revocation decisions and infringement counterclaims, or non-infringement declarations.

\subsection{Germany}

Because Germany operates a bifurcated system, i.e. patent infringement and patent validity cases are dealt with by different courts, we collected the patent infringement and nullity data separately. The 565 infringement cases were aggregated from Düsseldorf, Mannheim and Munich, the three largest patent litigation courts in Germany. ${ }^{24}$ For Düsseldorf, we used the official online North Rhine-Westphalia case database $^{25}$ by filtering all cases with the keyword 'patent' appearing in the judgment of the Landgericht. For Mannheim and Munich, we made use of Darts-IP to collect decision from the respective Landgericht. The existence of decisions at the appeal level (Oberlandesgericht and Bundesgerichtshof) was then verified. In total, we collected 472 infringement cases from Düsseldorf (and 171 related appellate decisions), 73 from Mannheim (and 22 related appellate decisions) and 20 from Munich (and 9 related appellate decisions). Thereafter, we extracted the patent codes from the database of the German Patent and Trade Mark Office and from Darts-IP. Nullity actions are handled by the German Federal Patent Court (Bundespatentgericht) in Munich with appeal to the Federal Court of Justice of Germany (Bundesgerichtshof). All revocation lawsuits with a decision falling within 2.5 years after an infringement decision were counted as counterclaims. ${ }^{26}$ Basing our search on the patent codes, we have gathered a total of 142 invalidity cases from the official Federal Patent Court and 23 from the Federal Court of Justice online databases ${ }^{27}$ and compared our results with the nullification actions listed in the Patent Gazette (Patentblatt). ${ }^{28}$

\footnotetext{
${ }^{24}$ In fact, the regional court in Düsseldorf hears the largest number of cases in Europe, according to data by Cremers et al. (2016).

25 Available under http://www.justiz.nrw.de.

26 Inversely, if a revocation decision occurred within the same timespan before the infringement decision, the case was excluded and considered as revocation with infringement counterclaim. The latter cases are rare, Hees and Braitmayer (2010) and Keukenschrijver (2011, pp. 73-74) estimate that over $90 \%$ of all revocation actions are filed in response to an infringement action. Since filing data is not publicly available, however, we are unable to distinguish actions according to the timing of their filing. Further, while we are able to manually confirm that a vast majority of the nullity actions in our dataset were brought by parties involved in the infringement lawsuit, or that the infringement decision explicitly made reference to the nullity action, a number of cases involved anonymous parties for which we cannot confirm the infringement-nullity pair with full certainty.

27 Available under https://www.bundespatentgericht.de.

28 Available under https://register.dpma.de/DPMAregister/Uebersicht. We estimate that our dataset covers over 50-60\% of all German patent infringement and counterclaim decisions rendered between 2008 and 2012, see Graham and Van Zeebroeck (2014) with indication that Darts-IP estimates its coverage to $50 \%$ in Germany for the years 2000-2009.
} 


\subsection{France}

In the absence of an official register for patent suits in France, we have built our dataset of 304 cases resp. 401 decisions from the IP data platform Darts-IP, the most exhaustive database in the field. ${ }^{29}$ This is underlined by the fact that, apart from the French Patent Office, Véron \& Associés is the main supplier of IP case data to the platform. ${ }^{30}$ Véron \& Associés has aggregated all decisions rendered by the Tribunal de Grande Instance (TGI) de Paris, the Cour d'Appel de Paris and the Cour de Cassation from the 1 January 2000 - therefore, covering all three appellate levels. Notably, the TGI provides the richest data source for French case data, since, even prior to the centralization of patent litigation in 2009 and the exclusive first instance jurisdiction of the TGI, the Parisian Court was already the most prominent patent court in France-hearing more than $50 \%$ of all cases. ${ }^{31}$

\subsection{United Kingdom}

The overwhelming majority of patent suits are heard in England and Wales, ${ }^{32}$ with a shared jurisdiction of the Patents High Court (PHC), part of the High Court of England and Wales, and the Intellectual Property Enterprise Court (IPEC; formerly the Patent County Courts). While the Patent County Courts historically dealt with smaller claims of less complex variety, with a market share of less than $10 \%,{ }^{33}$ the IPEC has become, after some restructuring in the court system, an effective forum for IP disputes in England and Wales. ${ }^{34}$ Our dataset is based on the PHC and the IPEC Diary, basically listing all cases scheduled for a hearing or an application. ${ }^{35}$ Thus, starting from the Diaries, we were able to collect 61 infringement cases (and 24 appellate decisions) from the website of the British and Irish Legal Information Institute, ${ }^{36}$ Thomson Reuter's Westlaw ${ }^{37}$ database and on Darts-IP. ${ }^{38}$

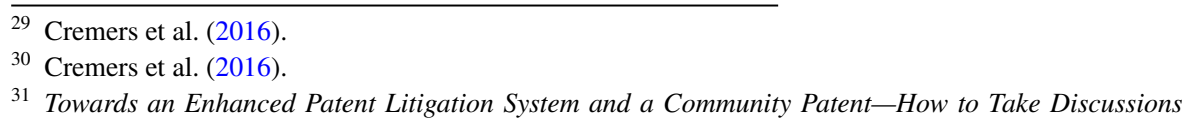

31 Towards an Enhanced Patent Litigation System and a Community Patent-How to Take Discussions Further (2017). We estimate that our dataset covers 75-90\% of all French patent infringement and counterclaim decisions rendered between 2008 and 2012, see Graham and Van Zeebroeck (2014) with indication that Darts-IP estimates its coverage to $90 \%$ in Germany for the years 2000-2009. A fraction of cases in our sample was rendered by the courts in Strasbourg and Rennes (6 and 1 infringement cases).

32 Hence, we excluded the by far less important litigation in Scotland and Northern Ireland.

33 See Helmers and McDonagh (2013) and Graham and Van Zeebroeck (2014).

34 Our evaluation indicates that, based on the 69 available court decisions listed on the IPEC Diary as per January 2011 on July 2015, the main share of rulings are issued in patent related cases (32.4\%) dominated by infringement trials (19.1\%), followed by copyright (20.6\%), trademark and design(19.1\% each), goodwill $(2.9 \%)$ and unavailable litigation (5.8\%).

35 Available for the PHC under https://www.justice.gov.uk/courts/court-lists/list-patents-court-diary and for the IPEC under https://www.justice.gov.uk/courts/court-lists/intellectual-property-enterprise-court -diary.

36 Available under https://www.bailii.org.

37 Available under https://www.westlaw.co.uk.

38 While the Diaries intend to be as accurate as possible, they do not furnish an exhaustive overview of UK patent litigation. Some settled cases are not listed and parties may, in some cases, request to not be listed (information derives from calls with the clerks in charge of keeping the IPEC and PHC Diaries). 


\section{Data coding}

\subsection{Decision coding}

We hand-coded all decisions, categorizing them across numerous dimensions, mainly by technology and industry, but also by the level of jurisdiction (first instance, intermediate appeal level and supreme court) and the nature of the ruling rendered (infringement vs. invalidity). The 'patent case' was our unit of analysis: each outcome was coded separately for each patent, even when they were assessed in the same verdict. A 'win' was reported if the patent holder could enforce its infringement claim before the courts, i.e. at least one of the claims was found to be infringed and that claim was, if challenged, upheld as valid.

\subsection{Patent quality}

Empirically speaking, patent quality is not a directly observable variable. Innovation economics scholars have been relying on inferences from patent metrics or survey methods. ${ }^{39}$ For instance, it has been shown that the private economic value of a patent, as estimated by inventors, correlated with the number of citations they yielded. ${ }^{40}$ Our microeconomic model suggests that patent quality depends on the broadness of the patent claim and definiteness of the patent, with a technology- or industry-specific scaling factor determining the relative weights. For our empirical identification strategy, we have matched both patent broadness and patent definiteness to empirical factors commonly used in the literature. In particular, we relied on an econometric factor model that is based on the work Lanjouw and Schankerman (2004). ${ }^{41}$

To arrive at the composite index, we formulate a factor model with separate broadness indicators of a patent: the number of claims and the number of distinct technological fields the invention is allocated to. ${ }^{42}$ We use a multiple-indicator model with patent definiteness at the latent common factor:

$$
y_{k i}=\lambda_{k} d_{i}+\beta X_{i}+\epsilon_{k i}
$$

\footnotetext{
Footnote 38 (continued)

We estimate that our dataset covers between 60 and $80 \%$ of all UK patent infringement and counterclaim decisions rendered between 2008 and 2012, see Graham and Van Zeebroeck (2014) with indication that Darts-IP estimates its coverage to 60-80\% in the UK for the years 2000-2009.

39 E.g. Gambardella et al. (2008).

40 E.g. Harhoff et al. (1999).

41 Lanjouw and Schankerman (2004); see also Hall et al. (2007), and Dumont (2014). for a recent use of the factor model to capture patent quality and link it to the damages in French patent lawsuits and Knoll et al. (2014) for a quality-adjusted count of patent applications. In addition, see OECD (2005) for a graphic view of the evolution of patent quality proxied by two composite indexes.

42 Both variables have been found to be associated with the expected value of patents. For claims, see Lanjouw and Schankerman (2004), and for patent scope, see Lerner (1994). The data was extracted from espacenet (www.espacenet.com). Note that the number of claims is the total number of both independent and dependent claims; and the number of technology fields represented by the number of 4-digit International Patent Classification subclasses (OECD 2005).
} 
where $y_{k i}$ is the observation of the $k$ th patent indicator for the $i$ 'th patent, $d_{i}$ is the patent's definiteness with factor loading $\lambda_{k}$ and $X_{i}$ are the patent broadness variables. The variance of $d$ is normalized by setting its variance to one $d \sim N(0,1)$. Any uncommon variation which is not related to the broadness indicators is captured by an idiosyncratic error $\epsilon_{k i}$, which is assumed to be independently drawn from a $N=0, \sigma_{k}^{2}$. The common definiteness factor $d_{i}$ is simply the unobserved characteristic of a patented innovation that influences all two of the broadness indicators $X_{i}$ : the number of claims and the number of technology classes. ${ }^{43}$

Thinking about our land law comparison above, where patent broadness is represented by the size of the land and patent definiteness by the fencing, we believe that the distinction makes intuitively sense. Since the patentable land of technological innovation is an ever-expanding land, patent definiteness is needed to fence off the different parts (patent claims) and parcels of the land (number of technologies). In particular, we relied on an econometric factor model. It should be noted that, following both our microeconomic model and Lanjouw and Schankerman (2004), the next logical step would have been to re-calculate different weights for the specific technologies and industries. However, we have decided on using the above uniform factors, which effectively treat technology and industry as exogenous factors with one common weighting, for all quality specifications. Instead, we decided to use both technology and industry as separate factors, as this allowed us to identify heterogeneity on that dimension more clearly in the main regression results. Furthermore, we collected additional patent quality proxies, in particular backward citations, forward citations and patent family size. ${ }^{44}$

\subsection{Technology coding}

Due to the limitations of the patent classification (such as the International Patent Classification) in capturing patents at a conceptual level, ${ }^{45}$ measuring the patent breadth requires hand-coding by technology field. ${ }^{46}$ We followed the classification developed by Master that distinguishes between mechanical, electronics, chemistry,

\footnotetext{
43 The factor loading matrix is presented in Appendix, "Patent quality results" section.

44 Espacenet defines forward citations as the number of patent applications or granted patents citing the patent document in question. As to patent family size, it relies on the (extended) INPADOC patent family in which '[m]embers of an extended patent family will have at least one priority in common with at least one other member-either directly or indirectly'. Backward citations include both patent documents and items of non-patent literature (although in the latter case, the document must have been classified using the Cooperative Patent Classification system or cited in a search report produced by the EPO to be listed).

45 The classifications are inadequate for delimiting technologies since they were designed with the purpose of identifying the function of the patent to facilitate prior art searches, see J. R. Allison, Lemley, Moore, and Trunkey (2004, pp. 28-29).

${ }^{46}$ In the words of Allison et al. (2004, pp. 28-29): 'if economists want to measure patent breadth, they will have to hand-code the patents by technology area or at least find a better measure than the ones that exist today'.
} 
biotechnology, software and optics patents (see Appendix, "Technology coding" section for further details). Each patent was assigned to one single technology area.

\subsection{Industry coding}

By determining the industries of use of patents, we aim at assessing a further dimension of patent litigation. Accordingly, we also followed the industry classification by Allison et al. (2015) and assigned each patent to one of the following industries: computer and other electronics, semiconductor, pharmaceuticals, medical devices, biotechnology, communications, transportation, construction, energy, goods and services for industry use, and goods and services for business use (see Appendix, "Industry coding" section for further details). According to our litigation data, a number of technology-industry pairs are more common than other. This does not come unexpected, but is rather a result of the limitations of the classification scheme that we have adopted from Allison et al. (2015). For instance many chemistry and biotechnology patents are employed in the pharmaceutical industry; while, on the contrary, optics patents are being used in even numbers across almost all industries. As many technologies are used in several industries, the distinction enables us to isolate inventions at a more refined level (see Fig. 5).

Figure 5 represents the 930 litigated patents at the technology-industry match level, that is it represents the patents of each technology and industry weighted by number. Technologies listed are (1) Biotechnology, (2) Chemistry, (3) Electronics, (4) Mechanical, (5) Optics, (6) Software; industries listed are (1) Biotechnology, (2) Communications, (3) Computer and Other Electronics, (4) Construction, (5) Energy, (6) Goods \& Services for Consumer Uses, (7) Goods \& Services for Industrial \& Business Uses, (8) Medical Devices, Methods \& Other Medical, (9) Pharmaceuticals, (10) Semiconductor, (11) Transportation.

\section{Descriptive results}

The readership recalls that only infringement disputes are recorded in our sample. That is, only lawsuits brought by the patent holder against one or several alleged infringers are examined. To counter such claims, infringers may either or both raise non-infringement defenses or validity arguments. Therefore, even when the patent is found to be infringed by the courts, the patent holder may overall lose at trial when his patent is declared invalid. Prevailing at trial therefore may require two wins, one on infringement and one on validity.

The picture painted by our data is complex. Patent litigation win rates are highest in Germany, with an average of about 53\%, followed by France, where an average of $37 \%$ of the claims have been successful. When patent holders brought infringement suits to the UK, they were successful in less than one of four cases (see Table 1). When increasing granularity, we find that the variation between infringement rates across countries, varying from about $56 \%$ to $64 \%$, was smaller than in invalidity 
rates. When patent validity was examined, the variance increased from $37 \%$ to $54 \%$. The low likelihood of success in validity trials in the UK must be underlined.

Of note is the great disparity in the share of patents that undergo validity examination. In the UK, validity counterclaims were raised in all but one dispute. In Germany, this share was of less than a quarter. This might be explained by institutional differences, since validity claims need to be raised in front of a separate specialized court in Germany. Similarly, the propensity of litigation to be appealed-or rather, to reach an appellate decision-varied by country. In the UK, $42 \%$ of the cases included at least one appellate decision, this share was of 32\% in Germany and of $28 \%$ in France. ${ }^{47}$ This might be indicative of the differences in type of cases and resources of litigants.

The division of litigated patent type is not congruous across jurisdiction (see Fig. 6). In France, upwards of $70 \%$ of all cases involved mechanical inventions. In contrast, a comparatively large share of litigated patents were chemistry and software technology patents in the UK. As to technology-specificity in Germany, it lied somehow in between France and the UK, although regional specialization must be noted. In Mannheim, about 55\% of the litigated patents were electronics or software patents, and very few optics and chemistry patents, while in Düsseldorf, the majority of disputes concerned mechanical patents.

From a descriptive perspective, we observe that the win rates by technology concealed remarkable variation, across and cross-country (see Table 2 and Appendix Tables 5 and6). There appears to be no tendency of one technology being particularly strong or weak across all three jurisdictions. The only exception were software patents. They underperformed consistently in validity trials across all jurisdictions. This mirrors the perception that software is less reliant on patents and that the line between patent-eligible software patent claims from ineligible ones is still blurry. ${ }^{48}$

Across industries, the only consistent theme is that pharmaceutical patents underperformed consistently in terms of infringement and validity (see Table 3 and Appendix Tables 7 and 8). The relative weakness of pharmaceutical patents is surprising, especially considering the traditional view that the current patent system is most accommodating for this industry and that the data presented by Allison et al. (2015) shows that pharmaceutical patents have fared well before US courts. ${ }^{49}$ As to

\footnotetext{
47 Note that for Germany, an appeal was coded if either the first instance infringement or invalidity decision was appealed, the number of appeals then was the total number of appellate decisions, that is an appeal of infringement and on invalidity would be recorded as two appeals.

${ }^{48}$ The patentability of computer program related inventions is regulated by Article 53 para. 2 and 3 EPC. The EPO considers that computer programs as such are not patentable. However, a computer program is patentable if it provides a technical contribution to the prior art, that is a further technical effect that goes beyond the normal physical interaction between the program and the computer, see Sterckx and Cockbain (2009); for the view that patents are not serving the software industry, see Webbink (2005).

49 Allison et al. (2015) stating that these results fit with the classical representation that pharmaceutical patents are strong and valuable, and are perceived as critical to protect R\&D investments, see amongst many Gawel (2006) summarizing that 'a well-functioning patent protection system is a prerequisite for attracting finance for costly pharmaceutical research, given its high failure rates, by ensuring that successful innovation is rewarded'.
} 


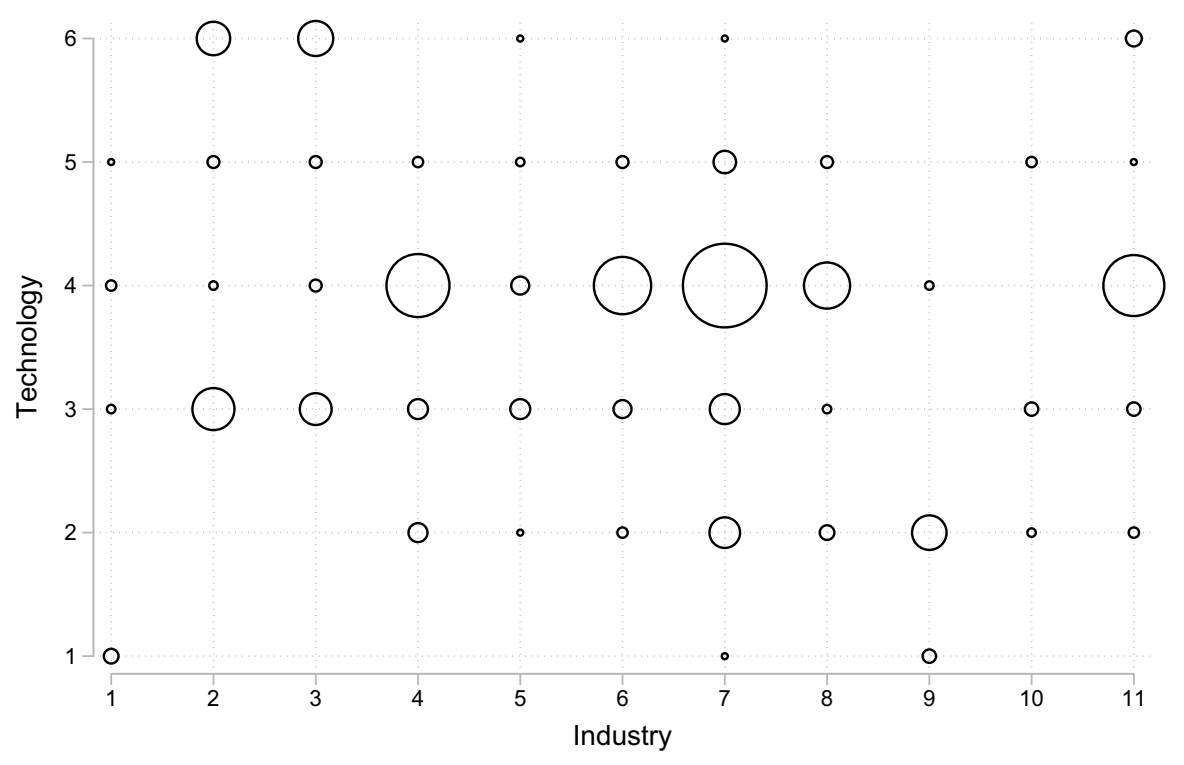

Fig. 5 Technology and industry patent pairs

the rest, the apparent commonality is the result of performing well in one country but not in the other.

As to the quality of the patents litigated before the three jurisdictions, we observe that the average quality was highest in the UK, followed by Germany and France (see Fig. 7). The distribution of the patent quality is skewed right, with an average $\bar{q}=0.19$ (see Fig. 8). In the Appendix, we further included the distribution of our patent quality proxy by technology and industry (see Appendix Figs. 12, 13).

Figures 9 and 10 present the partial relationship between two additional patent quality proxies, the number of forward citations and the family size, and the patent quality proxy for litigated patents. We observe a positive relationship: The higher patents ranked on our quality proxy, the higher their subsequent use (proxied by forward citations) and their geographical coverage (proxied by family size).

\section{Empirical results}

\subsection{Econometric specification}

We examine whether patent holders were more likely to enforce their patents with success depending on the country of litigation, the technology and industry of the patent, as well as the quality of the patent. We use a linear probability regression model. For dichotomous outcomes, such as whether the patent prevails at trial or not, linear regression models provide unbiased estimates of the conditional mean probability of an outcome and avoid incidental parameter bias even when including large number of intercepts. Specifically, we model the plaintiffs (discrete) success in 
Table 1 Win rates by country

\begin{tabular}{|c|c|c|c|c|c|c|}
\hline & \multicolumn{6}{|c|}{ Overall win rate by country } \\
\hline & \multicolumn{2}{|l|}{ Germany } & \multicolumn{2}{|l|}{ France } & \multicolumn{2}{|l|}{ UK } \\
\hline & Frequency & Win $\%$ & Frequency & Win $\%$ & Frequency & Win $\%$ \\
\hline Overall & 565 & 53.81 & 304 & 36.84 & 61 & 24.59 \\
\hline Infringement & 565 & 61.24 & 205 & 55.61 & 61 & 63.93 \\
\hline Validity & 140 & 49.29 & 225 & 54.22 & 60 & 36.66 \\
\hline
\end{tabular}
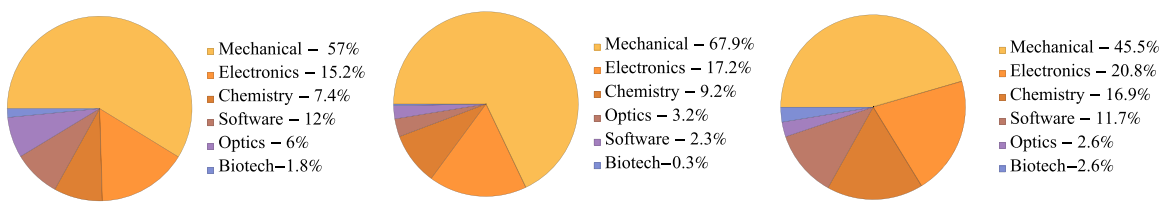

Fig. 6 Technology distribution in Germany, France and in the UK

Table 2 Overall win rate by technology

\begin{tabular}{|c|c|c|c|c|c|c|}
\hline \multirow[t]{3}{*}{ Technology } & \multicolumn{6}{|c|}{ Overall win rate by technology } \\
\hline & \multicolumn{2}{|l|}{ Germany } & \multicolumn{2}{|l|}{ France } & \multicolumn{2}{|l|}{ UK } \\
\hline & Frequency & Win $\%$ & Frequency & Win $\%$ & Frequency & Win \% \\
\hline Mechanical & 325 & 56.31 & 217 & 35.94 & 32 & 31.25 \\
\hline Electronics & 86 & 52.33 & 47 & 53.19 & 11 & 10.0 \\
\hline Chemistry & 42 & 45.24 & 30 & 23.33 & 11 & 36.36 \\
\hline Software & 68 & 42.65 & 4 & 0 & 5 & 0 \\
\hline Optics & 34 & 58.82 & 5 & 40.0 & 1 & 0 \\
\hline Biotechnology & 10 & 80.0 & 1 & 0.0 & 2 & 0 \\
\hline Total & 565 & 53.81 & 304 & 36.84 & 61 & 24.59 \\
\hline
\end{tabular}

case $i$, denoted as $Y_{i}$, as a function of technology $T$, industry $I$, country $C$ and patent quality $Q$. We estimate the model below:

$$
Y_{i}=\alpha+\beta_{1} T_{i}+\beta_{2} I_{i}+\beta_{3} C_{i}+\beta_{4} T_{i} \cdot I_{i}+\beta_{5} Q_{i}+k+\epsilon_{i}
$$

where the dependent variable is the case outcome, with $Y_{i}$ equal to 1 if the claim is successful at trial and 0 if the claim is not upheld. A 'win' was reported if the patent holder could enforce its infringement claim before the courts, i.e. at least one of the claims was found to be infringed and that claim was, if challenged, upheld as valid. Two further specifications use the infringement outcome and the invalidity outcome as dependent variable, respectively.

$T, I$ and $C$ are indicators to control for level differences across these factors. $T \cdot I$ denotes the full set of interactions between technology and industry dummies to 
Table 3 Infringement by industry

\begin{tabular}{|c|c|c|c|c|c|c|}
\hline \multirow[t]{3}{*}{ Technology } & \multicolumn{6}{|c|}{ Infringement win rate by industry } \\
\hline & \multicolumn{2}{|l|}{ Germany } & \multicolumn{2}{|l|}{ France } & \multicolumn{2}{|l|}{ UK } \\
\hline & Frequency & Win $\%$ & Frequency & Win $\%$ & Frequency & Win $\%$ \\
\hline Goods \& services for industrial uses & 161 & 60.87 & 51 & 47.06 & 17 & 88.24 \\
\hline Construction & 74 & 43.24 & 37 & 37.83 & 2 & 100.0 \\
\hline Transportation & 56 & 62.50 & 41 & 60.98 & 7 & 42.86 \\
\hline Goods \& services for consumer uses & 56 & 64.29 & 36 & 66.67 & 3 & 100.0 \\
\hline Medical devices, methods \& medical & 47 & 68.09 & 6 & 33.30 & 9 & 22.20 \\
\hline Computer and other electronics & 55 & 65.45 & 9 & 66.67 & 2 & 50.00 \\
\hline Communications & 61 & 62.30 & 12 & 100.0 & 12 & 91.67 \\
\hline Pharmaceuticals & 16 & 50.0 & 10 & 60.0 & 9 & 22.20 \\
\hline Energy & 18 & 77.78 & 3 & 33.3 & 2 & 0 \\
\hline Semiconductor & 9 & 66.67 & - & - & - & - \\
\hline Biotechnology & 12 & 91.67 & - & - & - & - \\
\hline Total & 565 & 61.24 & 215 & 55.61 & 61 & 63.93 \\
\hline
\end{tabular}

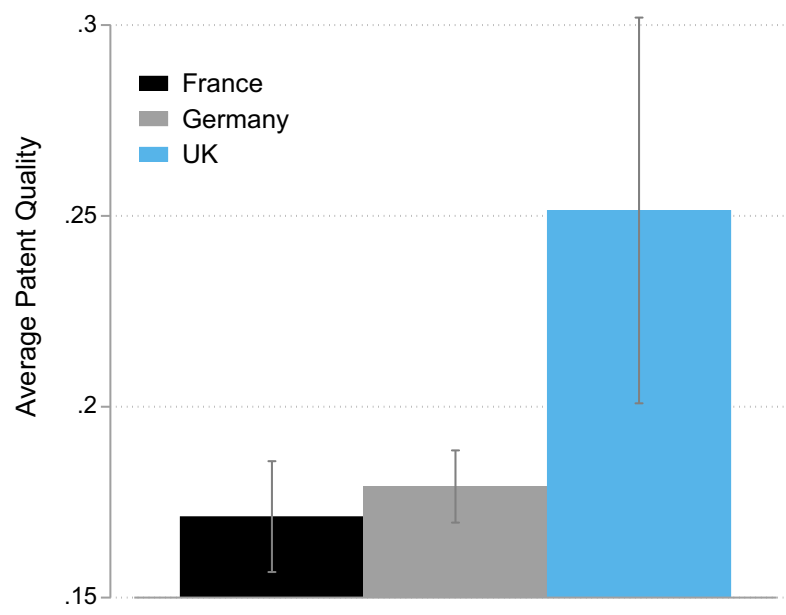

Fig. 7 Average patent quality

control for industry-technology fixed effects. $Q$ is the patent quality proxy we developed, a continuous variable between $\sim N(0,1)$ for the patent under dispute in case $i . k$ represents the fixed effects for the year of the trial and the fixed effects for the number of appeals at trial. ${ }^{50}$ We estimate $\beta$ coefficients for the different factors. $\epsilon$ is an error

\footnotetext{
${ }^{50}$ Where the year of trial represents the year of the first instance decision and the number of appeals is the number of appellate decisions.
} 


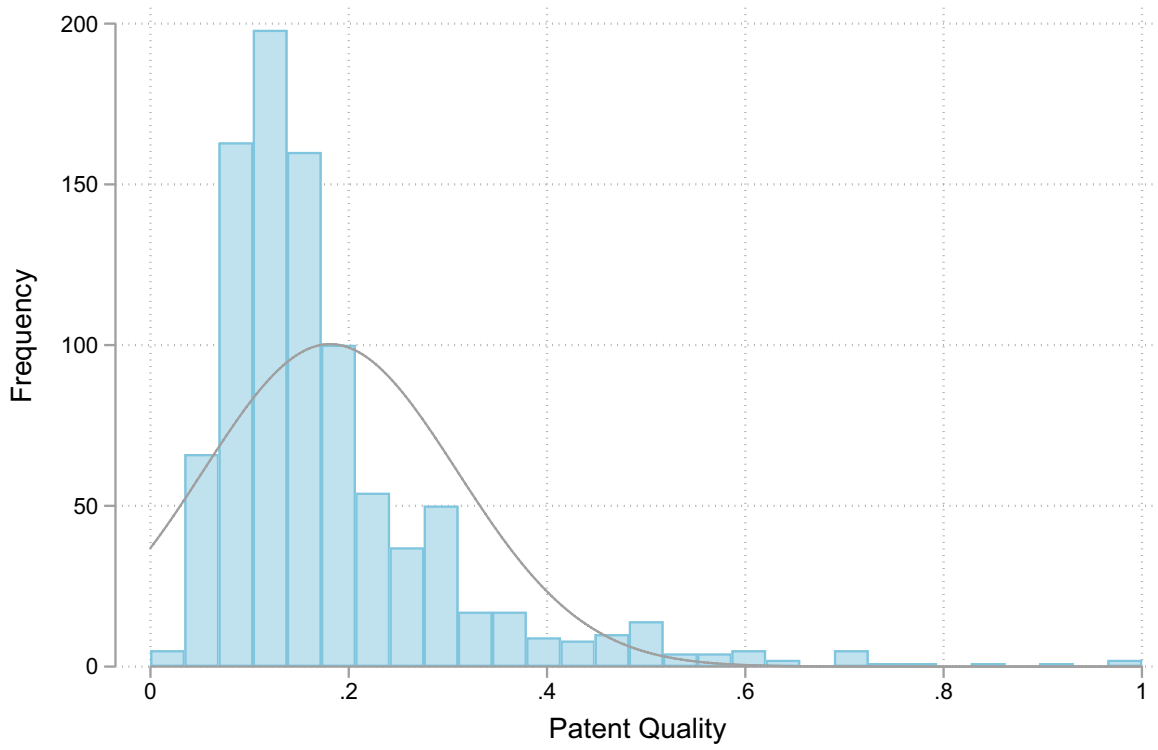

Fig. 8 Distribution patent quality

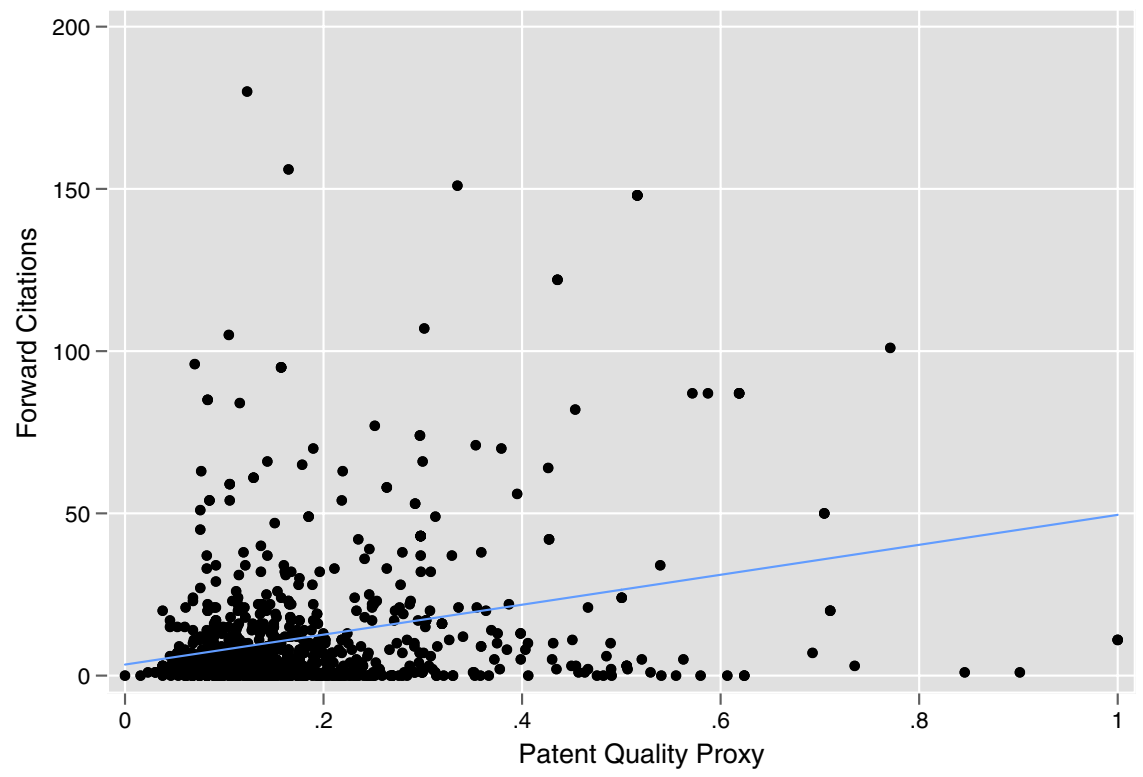

Fig. 9 Correlation forward citations and patent quality proxy

term. We consistently use 'chemistry' as the contrast dummy for technology, 'goods and services for consumer uses' for industry and Germany for the country indicator. We use heteroscedasticity robust standard errors to determine significance. 


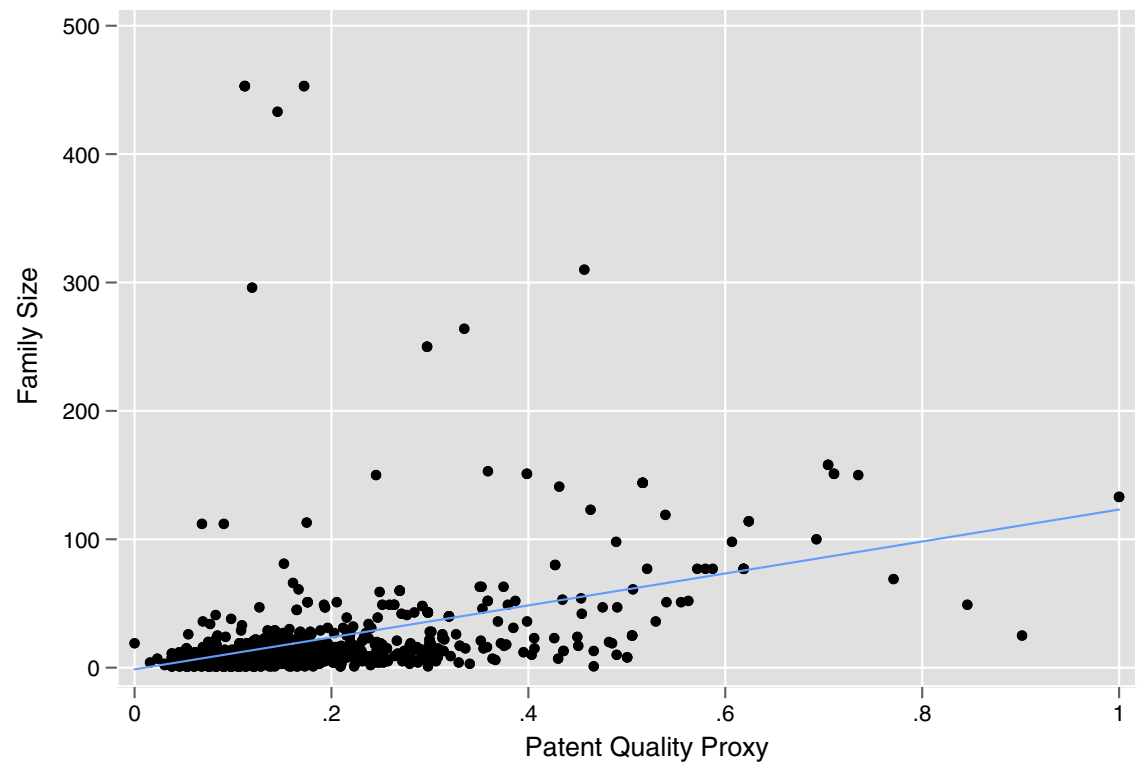

Fig. 10 Correlation family size and patent quality proxy

\subsection{Results}

The linear regressions we conducted to test for the effect of the country of litigation, technology, industry and quality of the patent on the likelihood of success of patent holders led to the following results (see Regression Table 4).

\subsubsection{Country}

Overall, patents litigated before the courts in Germany were significantly more likely to prevail than patents in France $(\beta=-.18, p<.01)$ and in the UK $(\beta=-0.279$, $p<.01$, when controlling for technologies, industries, patent quality, and characteristics of the trial. Patent holders in Germany had a $18 \%$ higher chance of winning at trial than litigants in France; this probability was even $28 \%$ higher compared to patent holders in the UK. In other words, patent holders in Germany were more likely to enforce their patents with success without regard to the underlying patent. We then distinguish between the decision on the infringement and on the validity of the patent. We find that there was no significant effect of the country variable on infringement outcomes. By contrast, and in line with the descriptive results, patents undergoing validity counterclaims in the UK were significantly more likely to be invalidated than their counterparts in Germany $(\beta=0.145, p<.1)$. 


\subsubsection{Technology}

The technology underlying patents was a significant predictor for the overall outcome at trial, as well as for the individual infringement and invalidity cases. Surprisingly, several technologies were predictors for lower likelihood to prevail at infringement trials, but higher likelihood to win on validity grounds. Most strikingly, electronics and mechanical patents had a $70 \%$ and $28 \%$ lower likelihood to win on infringement $(\beta=-.70, p<.01$ and $\beta=-.28, p<.01)$, but a $98 \%$ and $75 \%$ higher probability to win on invalidity compared to chemistry patents $(\beta=-.983, p<.01$ and $\beta=-.75, p<.01)$. Patents in two technologies, software and biotechnology, were associated with lower probabilities of prevailing at validity trials $(\beta=0.2$, $p<.05$ and $\beta=.40, p<.05)$.

\subsubsection{Industry}

A number of industries were associated with a significantly higher or lower likelihood to win at trial. Patents in the pharmaceutical industry were significantly more likely to prevail overall $(\beta=0.355, p<.01)$ and on validity grounds $(\beta=-0.451$, $p<.01$ ), but were significantly less likely to win on infringement relative to patents from consumer goods and services $(\beta=-0.569, p<.01)$. On the contrary, biotechnology patents were significantly more likely to win infringement disputes, but less likely to win validity trials ( $\beta=0.387 p<.1$ and $\beta=0.696 p<.01$ ); with a caveat due to the low sample size. Patents deployed in industries such as communications, computer and other electronics and construction, performed strongly at validity trials, but were associated with lower win rates at the infringement stage (e.g. for computer and other electronics, $\beta=-0.609, p<.01$ an $\beta=-1.242, p<.01$ ).

\subsubsection{Quality}

The quality of the patent undergoing litigation was a significant predictor of both its definitive success and the infringement outcome $(\beta=0.437, p<.01$ and $\beta=0.266$, $p<.1$ ). There was, however, no significant effect of the patent quality proxy on the outcome at invalidity trial. Patents of higher quality were more likely to prevail in litigation and to be found infringed, but not to be held valid. Even when excluding the UK, the patent quality proxy did not correlate with the likelihood of patent holders to prevail for validity challenges. The comparison with classical proxies of patent quality yields mixed results. The count of forward citations of patents was found to be significantly associated with the likelihood of these patents to prevail on overall, infringement, and invalidity outcomes. On the other hand, family size and backward citations did not correlate with patent litigation outcomes (except for backward citations at the infringement level). 


\subsubsection{Technology • industry}

To illustrate the interaction effects between the technology and industry of the patented invention, we compute and graph the predicted probabilities of an overall win in Fig. 11 (see further Appendix Figs. 14, 15). Illustratively, when software patents were employed in the transportation industry (e.g. automotive industry), they had a neutral effect on litigation outcomes, while when used in the communications (e.g. smartphones), this effect was negative.

We test the joint significance of the technology dummies (and interaction terms) using a Wald-test. We find that the technology terms are jointly significant when the outcome variable is "Overall" ( $p$ value $=0.006)$ and "Invalidity" ( $p$ value $=0.0204)$, but insignificant when the outcome variable is "Infringement" ( $p$ value $=0.2948)$. This supports our hypothesis that the technology and industry of the litigated patent is directional of the outcome of patent litigation.

\section{Discussion}

\subsection{Differences across jurisdiction}

Our data suggest that Germany should be the most attractive forum for patent holders, as patents claims are most successfully litigated there. Overall, the choice of forum was decisive; although for different reasons depending on the particular jurisdiction. The courts in the UK appears to be somewhat biased against patent holders; that is they were more likely to invalidate patents irrespective of the characteristics of the underlying patents. On the other hand, the outcome variation in France seems to result from higher hare of patents undergoing validity trials and in the particular industries at stake.

\subsubsection{Germany and the UK}

The reputation of the UK courts is to be 'anti-patents', that is to be an unfriendly jurisdiction for patent holders because of low win rates and high costs of litigation. ${ }^{51}$ As such, the UK is thought to constitute a propitious jurisdiction for challenging the validity of patents or requesting declarations of non-infringement. ${ }^{52}$ In line with this perception, we find that less than a quarter of all patent infringement lawsuits ultimately resulted in a win. By distinguishing between infringement and the validity challenge raised, a more refined picture emerges. The UK courts were awarding infringement in over two third of all instances, the highest rate amongst the three

\footnotetext{
${ }^{51}$ Illustratively, when the alleged infringer brought the case to the Patents Courts in London, patent holders only won in 14\% of the cases in 2006 to 2009, see Elmer and Lewis (2014), and further Helmers and McDonagh (2013).

${ }^{52}$ Moss et al. (2010) reviewing this perception and contending that the courts became more friendly to the patentees in 2008 and 2009.
} 
Table 4 Regression results

\begin{tabular}{|c|c|c|c|}
\hline & Definitive win & Infringement & Invalidity \\
\hline \multicolumn{4}{|l|}{ Country } \\
\hline France & $\begin{array}{l}-0.180 * * * \\
(-5.02)\end{array}$ & $\begin{array}{l}-0.0419 \\
(-0.96)\end{array}$ & $\begin{array}{l}0.0759 \\
(1.21)\end{array}$ \\
\hline UK & $\begin{array}{l}-0.279^{* * *} \\
(-4.05)\end{array}$ & $\begin{array}{l}0.0529 \\
(0.77)\end{array}$ & $\begin{array}{l}0.145^{*} \\
(1.85)\end{array}$ \\
\hline \multicolumn{4}{|l|}{ Technology } \\
\hline Biotechnology & $\begin{array}{l}-0.143 \\
(-0.64)\end{array}$ & $\begin{array}{l}-0.274 \\
(-1.07)\end{array}$ & $\begin{array}{l}0.400^{* *} \\
(2.45)\end{array}$ \\
\hline Electronics & $\begin{array}{l}0.452 * * * \\
(2.74)\end{array}$ & $\begin{array}{l}-0.700 * * * \\
(-4.26)\end{array}$ & $\begin{array}{l}-0.983 * * * \\
(-7.15)\end{array}$ \\
\hline Mechanical & $\begin{array}{l}0.667 * * * \\
(8.91)\end{array}$ & $\begin{array}{l}-0.280 * * * \\
(-3.95)\end{array}$ & $\begin{array}{l}-0.750 * * * \\
(-6.26)\end{array}$ \\
\hline Optics & $\begin{array}{l}0.401 \\
(1.48)\end{array}$ & $\begin{array}{l}-0.386^{*} \\
(-1.69)\end{array}$ & $\begin{array}{l}-0.519 \\
(-1.32)\end{array}$ \\
\hline Software & $\begin{array}{l}0.434 * * \\
(2.00)\end{array}$ & $\begin{array}{l}0.772 * * * \\
(3.03)\end{array}$ & $\begin{array}{l}0.200 * * \\
(2.02)\end{array}$ \\
\hline \multicolumn{4}{|l|}{ Industry } \\
\hline Biotechnology & $\begin{array}{l}0.564 * * \\
(2.11)\end{array}$ & $\begin{array}{l}0.387^{*} \\
(1.69)\end{array}$ & $\begin{array}{l}0.696^{* * * *} \\
(5.74)\end{array}$ \\
\hline Communications & $\begin{array}{l}-0.233 \\
(-0.96)\end{array}$ & $\begin{array}{l}-1.242^{* * * *} \\
(-4.07)\end{array}$ & $\begin{array}{l}-0.426 * * * \\
(-2.70)\end{array}$ \\
\hline Computer and other electronics & $\begin{array}{l}-0.0767 \\
(-0.32)\end{array}$ & $\begin{array}{l}-1.187 * * * \\
(-4.29)\end{array}$ & $\begin{array}{l}-0.609 * * * \\
(-3.28)\end{array}$ \\
\hline Construction & $\begin{array}{l}0.377 * * \\
(2.10)\end{array}$ & $\begin{array}{l}-0.634 * * * \\
(-3.82)\end{array}$ & $\begin{array}{l}-1.166^{* * *} \\
(-8.35)\end{array}$ \\
\hline Energy & $\begin{array}{l}0.915 * * * \\
(15.82)\end{array}$ & $\begin{array}{l}-0.0535 \\
(-1.03)\end{array}$ & $\begin{array}{l}-0.103 \\
(-0.40)\end{array}$ \\
\hline Goods \& services for industrial uses & $\begin{array}{l}0.395 * * * \\
(3.06)\end{array}$ & $\begin{array}{l}-0.469 * * * \\
(-3.72)\end{array}$ & $\begin{array}{l}-0.675^{* * *} \\
(-3.68)\end{array}$ \\
\hline Medical Devices, methods \& other medical & $\begin{array}{l}0.494 * * \\
(2.50)\end{array}$ & $\begin{array}{l}-0.219 \\
(-1.13)\end{array}$ & $\begin{array}{l}-0.623 \\
(-1.44)\end{array}$ \\
\hline Pharmaceuticals & $\begin{array}{l}0.355^{* * * *} \\
(3.53)\end{array}$ & $\begin{array}{l}-0.569 * * * \\
(-5.09)\end{array}$ & $\begin{array}{l}-0.451 * * * \\
(-2.99)\end{array}$ \\
\hline Semiconductor & $\begin{array}{l}0.388 \\
(1.34)\end{array}$ & $\begin{array}{l}-0.109 \\
(-1.55)\end{array}$ & $\begin{array}{l}-0.143 \\
(-1.37)\end{array}$ \\
\hline Transportation & $\begin{array}{l}0.106 \\
(0.91)\end{array}$ & $\begin{array}{l}-1.196^{* * *} \\
(-6.75)\end{array}$ & $\begin{array}{l}-0.133 \\
(-1.56)\end{array}$ \\
\hline \multicolumn{4}{|l|}{ Patent quality } \\
\hline Quality proxy & $\begin{array}{l}0.437 * * * \\
(3.10)\end{array}$ & $\begin{array}{l}0.266^{*} \\
(1.89)\end{array}$ & $\begin{array}{l}-0.167 \\
(-0.83)\end{array}$ \\
\hline Bwd citations & $\begin{array}{l}-0.00466 \\
(-1.46)\end{array}$ & $\begin{array}{l}-0.00706^{* *} \\
(-2.05)\end{array}$ & $\begin{array}{l}-0.000876 \\
(-0.24)\end{array}$ \\
\hline
\end{tabular}


Table 4 (continued)

\begin{tabular}{llll}
\hline & Definitive win & Infringement & Invalidity \\
\hline Fwd citations & $0.00174^{* *}$ & $0.00151^{*}$ & $-0.00165^{*}$ \\
& $(2.40)$ & $(1.94)$ & $(-1.70)$ \\
Family size & 0.0000305 & 0.000430 & 0.0000244 \\
& $(0.08)$ & $(1.13)$ & $(0.09)$ \\
Constant & -0.0769 & $0.939^{* * *}$ & $1.305^{* * *}$ \\
& $(-1.04)$ & $(12.78)$ & $(11.48)$ \\
Year fixed effects & Yes & Yes & Yes \\
Appeals fixed effects & Yes & Yes & Yes \\
Technology-industry fixed effects & Yes & Yes & Yes \\
$R^{2}$ & 0.1674 & 0.1212 & 0.2209 \\
Observations & 930 & 831 & 425 \\
\hline
\end{tabular}

Robust standard errors in parentheses. The table presents the results of three linear probability models. The dependent variable is the discrete patent litigation outcome, one if the claim is successful, and zero otherwise. The independent variables are technology, industry and country, all indicator variables, and the computed quality index. The contrast dummies for the indicator variables are "Chemistry", "Consumer Goods and Services" and Germany for technology, industry and country, respectively

$* p<.1 ; * * p<.05 ; * * * p<.01$

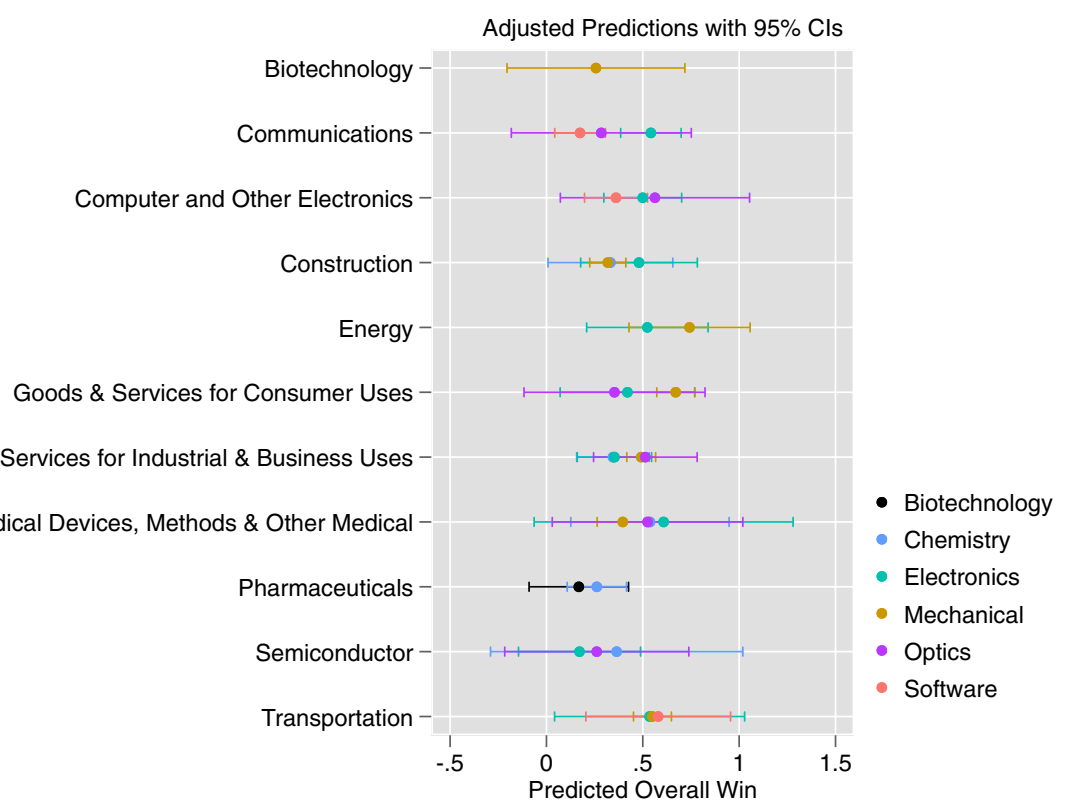

Fig. 11 Predicted probabilities technology industry-interaction

countries of study. The crux of the matter lies in the invalidity counterclaims. Controlling for the patent at stake, its technology, industry and quality, patents were 
significantly more likely to be invalidated in the UK than in Germany. This implies that there may exist a negative bias against patents in validity trials in the UK, compared to Germany. It is unclear whether this negative bias against patent holders suggested by our data stems from differences in procedural rules, such as more stringent disclosure and expert witness rules in the UK, or from the judge-specific application of the substantive patent law. Irrespective of the origin, such a stricter validity standard contradicts the notion of a harmonized European patent system.

\subsubsection{Germany and France}

When comparing the success chances of patent holders in Germany and with those in France, we find that although there is a significant difference in the overall success probability, this is not the case for the individual infringement and invalidity outcomes. This implies that the difference between the two jurisdictions does not lie in a bias of the courts, but rather in the share of patents undergoing validity challenge and in the characteristics of the patents at stake. Over two thirds of all French patents were subject to validity counterclaims. By contrast, in Germany, this share was less than a quarter. While in both cases close to half of the patents were found to be invalid, the difference in the share of patents undergoing such examination led to a substantial difference in the overall outcome. As mentioned above, the most probable cause of this is the German institutional setting, which has a separate trial procedure for invalidity claims. Under the German patent litigation system, the alleged infringer must file a lawsuit with a specialized patent court, rather than bringing the validity defense within the infringement proceedings. ${ }^{53}$ Furthermore, we find level differences in the industries of the patents litigated. The share of patents from the construction industry, which we find to be significantly more likely to lose on infringement grounds, was highest in France. There were also more pharmaceutical patents respectively and less biotechnology patents litigated in France compared to Germany. Those that were litigated, however, had different win rates in infringement disputes. Finally, patents in Germany were, on average, of higher quality. The higher the quality, the more likely the patent was to prevail in infringement disputes. $^{54}$

\subsubsection{France and the UK}

Patent holders in France were overall more likely to prevail compared to the UK, but this did not result from differences in the appraisal of infringement or invalidity. There was no significant impact of the country variable on both of these outcomes,

\footnotetext{
53 For a theoretical and empirical investigation of the costs and benefits of bifurcated systems, see Cremers et al. (2016) demonstrating that infringers are less likely to challenge validity in bifurcated systems than in non-bifurcared ones.

54 Surveys have shown that most companies are unsatisfied with the amount of the reimbursement of procedural costs in French patent litigation, qualifying them as 'way too low', as well as with the amount of damages awarded, while they were satisfied with the reimbursement in Germany, see Triet and Santarelli (2000); see also Graham and Van Zeebroeck (2014).
} 
suggesting that differences in the technology, industry, or quality of the patents explained the overall difference. France, for instance, was the ground-field for only very few software patent disputes, which were significantly more likely to be found invalid. A large part of the litigated patents in France were in the mechanical technology category, which performed strongly in court. ${ }^{55}$ When contrasting France to the UK, the selection effects in the UK and the level differences in validity challenges, rather than the forum, appear to explain the differences in outcome.

Despite historical differences in patent litigation outcomes, patent holders still litigate across jurisdictions. In other words, the most patent-friendly jurisdictionby most accounts Germany-does not hear the entirety of patent cases in Europe. It is unclear whether this is a result or combination of filing strategies, home bias, infringement basis, or other strategic considerations.

\subsection{Differences across patent quality}

Our empirical finding that patent quality significantly predicts patent litigation outcome corresponds with the prediction of our model. As discussed above, we hypothesize that the judge will make an assessment of the patent quality at trial, resulting in the assignment of a 'judicial' patent quality which determines the success probability at trial. We acknowledge that our notion of patent quality focuses on the standalone patent quality only, not on its trial path or characteristics of the applicants, inventors or judges. ${ }^{56}$ This being said, our patent quality measure was an significant predictor with respect to overall outcomes and infringement outcome at trial. The proxy was in line with the predictions provided by forward citations, the most commonly used proxy for patent quality.

Patent quality provides further insights on the fragmentation of the European enforcement system. According to our research, fragmentation in Europe stems largely from differences in the appraisal of validity counterclaims. In that regard, our empirical finding that validity decisions are not associated with patent quality provides an interesting insight. One explanation for this might be that patent holders have better access to information about the validity of their patent and existing prior art, and could thus be in a stronger position to defend their case, making the case outcome less dependent on absolute patent (or at least our empirical estimator of the latter).

The jurisdiction with the highest quality patents was the UK, where the definitive win rate was much lower than in France and in Germany. This should be put in the context of patent litigation costs in the UK, which are substantially higher than in the other two jurisdictions. This may crowd out lower quality inventions,

\footnotetext{
55 According to findings by Véron (2010), the incidence of litigation was higher for mechanical patents for the time span 2000-2009 than for any other technology.

56 In the United States, Mann and Underweiser (2012) found statistically significant relations between validity decisions and ex ante aspects of the prosecution history such as the existence of internal patent office appeals; for an overview of the multitude studies relating to the effects of gender, religion or political preferences on case outcomes within the past two decades, see Choi and Gulati (2008).
} 
where the parties prefer to settle the dispute or even entirely renounce to the enforcement of their rights when the expected payoff from trial is too low. This enforcement threshold may lead to a secondary effect of market distortion by discouraging the enforcement of valid (but rationally unenforceable) patents. ${ }^{57}$ In other words, the UK system could be said to impose a 'tax' on innovation as UK innovators have lower incentives to invest in patents that cannot be enforced purely on the basis of litigation costs rather than substantive aspects. ${ }^{58}$

\subsection{Limitations}

A number of limitations, mainly potential selection biases affect our analysis and conclusion. In the absence of data on settlements, it is unclear whether our patent litigation data constitutes a representative subsample of both patent disputes and the entire patent universe. ${ }^{59}$ Furthermore, data gathering limitations made it impossible to collect the entire population of lawsuits resulting in a decision on the merits. Our empirical analysis fundamentally rests on the assumption that the data is representative of all lawsuits, but we do not have any strong evidence that this is or is not the case. Issues such as differences in data representation by country or by certain courts at the national level represent limitations. ${ }^{60}$ The country-by-country comparison is complicated by selection effects occurring at the national level.

To render the comparison possible, we contend that the selection mechanism that our theoretical model posits, accounts for all of the selection occurring. Under our model, and in contrast to Priest and Klein, the cases at trial do not necessarily have a $50 \%$ chance of winning. Unlike under Priest and Klein, the divergent expectations of the parties will result in a first selection of the cases proceeding to trial. However, at trial, unlike under Priest and Klein, we assume that the judicial standard will also be subject to an estimation error. Said estimation error, which we term 'definiteness', is a component of patent quality. In the empirical estimation strategy, this judicial estimation error corresponds to the unmeasurable component of patent quality. Should our model and assumptions fit the realities of patent litigation, this would mean that we are in a position to claim that patent litigation in Europe is country-specific. Despite the harmonization efforts, this would imply that systematic differences in the likelihood of patents to be enforced with success exist across jurisdictions. Put

\footnotetext{
57 Ellis (1999) '[i]t is, simply put, that the escalating, indeed skyrocketing litigation costs of the 1970s and 1980s have distorted patent markets and patent economics. Put another way, it is my observation that the escalating costs associated with litigating patent infringement and validity issues discourage challenges to patents, thereby essentially equating the entry barriers for presumptively valid, but weaker patents with those entry barriers associated with strong or judicially tested patents'.

58 See Bessen and Michael (2007) for costly litigation as tax on innovation when it flows from the risk of unavoidable infringement.

59 Cremers and Schliessler (2015) with the finding that the overall settlement rate is of $62 \%$ in Germany (using a broad definition of settlement including unilaterally dropped cases and cases dropped in agreement of the parties) or $44 \%$ (using explicitly stated settled cases).

60 The settlement rate across German courts ranges from $59 \%$ in Düsseldorf to $70 \%$ in Munich, see Cremers and Schliessler (2015).
} 
otherwise, patents with similar characteristics and similar strength would not, in the limit, reach similar outcomes.

However, if settlement in the shadow of law, data gathering limitations, and national selection effects are in fact the explanatory factors of our findings, the implications are less profound. In this alternate story, a small yet important subset of all patent disputes is at stake. The analysis of this non-representative subset would suggest that the filtering of patents through litigation results in a technologically and quality-wise uneven group of patents, that differs widely by country. Therefore, in the European system, the filtering process would be country specific. Should this be true, it must nonetheless be asked whether these differences are random or arise because of institutional differences between national or judicial practices by courts. Should the filtering be non-random, this would illustrate how the lack of harmonization of the European patent enforcement system leads to a widely country-specific, disparate case population at trial.

\subsection{The future}

The Unified Patent Court (UPC) is a proposed supra-national common court which is supposed to commence operations within the near future. It has the goal of harmonizing patent enforcement by providing a one-stop litigation forum for patent disputes. In an effort to bring greater harmony and cross-national predictability to patent litigation, a single court shall, in principle, deal with all civil litigation relating to European patents. This means that the UPC will have exclusive jurisdiction over all infringement and invalidation proceedings for European patents (including the new Unitary Patent) throughout the 25 European territories involved (all EU Member States except Spain, Poland and Croatia). ${ }^{61}$ The Court of First Instance will have a Central Division seated in Paris and sections in Munich and London. Within the Divisions, the cases will be attributed based on subject matter with London inter alia specializing on Chemistry, Munich on Mechanical Engineering and Paris on Physics and Fixed Constructions. ${ }^{62}$ Furthermore, Member States may set up local division, in general one per state with the exception for Germany with four local divisions, and regional divisions such as the 'Nordic-Baltic' regional division in Stockholm. ${ }^{63}$ Appeals on points of law and facts can be lodged with the Court of Appeal, located in Luxembourg. Furthermore, questions on the interpretation in matters of EU law may be submitted to the European Court of Justice. The Unitary Patent, which is a new type of European patent with validity in all 25 states, will be granted once the Unified Patent Court enters into force. ${ }^{64}$ The court will enter into force when at least thirteen states, including the three largest patent granting states

\footnotetext{
61 See Mahne (2012) for a historical perspective and Xenos (2013) for a criticism of the lack of democratic process-making as the UPC establishes a monopolistic source of legal power.

62 See Annex II of the Unified Patent Court Agreement.

63 See Art. 7 para. 3 Unified Patent Court Agreement and Impact of the Unitary Patent Protection and the Unified Patent Court in the Nordic-Baltic Region (2014).

64 Pinckney (2015) and Johnson and Maunder (2017).
} 
France, Germany and the UK, have ratified the Agreement on the Unified Patent Court. The UK ratified the UPC Agreement in April 2018, but the impact of Brexit and the capacity of the UK to remain a member of the UPC after its potential withdrawal from the EU are unclear. ${ }^{65}$ In Germany, a constitutional complaint pending in the German Federal Constitutional Court regarding the implementation law passed by the German Parliament is causing delay to the ratification. At the time of writing this article, the fate of the UPC therefore remains undetermined. Despite these uncertainties, the UPC Preparatory Committee is currently proceeding on planning, among others, for the recruitment and training of UPC judges. ${ }^{66}$ The latter, namely the training of patent judges on the same cases will be key to achieving homogeneity beyond the harmonization of statutory requirements, as it will reduce intra-UPC heterogeneity in patent decisions.

The ultimate aim of the UPC is to provide for a one-stop litigation forum for patent disputes, thus enabling litigation with European-wide effect. The court shall, thus, avoid or reduce intra-community trade barriers, the high costs of parallel litigations, and inconsistent decisions or strategic litigation that may follow from a fragmented court system. ${ }^{67}$ Harhoff (2009) estimated that the total private savings from having access to a unified patent court would range between EUR 147 to 289 million annually. A variety of challenges will mark both the transitional and longrun operation of the court, creating barriers to such goals. ${ }^{68}$ Firstly, there will be a transitional period of seven to fourteen years, during which national courts and the UPC will have parallel jurisdiction over actions concerning (non-unitary) European patents. ${ }^{69}$ The potential for forum shopping and divergences in decisions will not vanish for the foreseeable future and will also be part of the new system. In particular, infringement lawsuits can be brought before local and regional divisions, which will have jurisdiction to decide on potential counterclaims for revocation or referrals to the Central Division. ${ }^{70}$ Pan-European litigation will not be a concrete possibility as thirteen state parties to the European Patent Convention will not be part of the

\footnotetext{
65 For the widely debated topic of the participation of the UK in the UPC, see, e.g., Ohly and Streinz (2017); Lamping and Ullrich (2018); and Tilmann (2006).

66 At a conference, chairman Alexander Ramsay of the UPC Preparatory Committee said work to prepare for the UP system is going on: '[w]e are trying to use the time that we have to make sure the system works when we're starting.', see http://patentblog.kluweriplaw.com/2018/02/15/plans-training-judge s-unified-patent-court-ready.

67 See, e.g., Harhoff (2009); Mejer and van Pottelsberghe de la Potterie (2009); Undesirable effects of parallel litigation include the added financial burden of proceeding in different courts, the consumption of judicial resources in multiple jurisdictions and inconsistent decisions, see Furata (1995).

68 See, e.g., Romandini and Klicznik (2013) and Brandi-Dohrn (2012).

69 Art. 83 Unified Patent Court Agreement. Parallel litigation during the transitional period raise a number of questions of lis pendens, see an overview under http://eplaw.org/eu-division-of-jurisdiction-intransitional-period.

70 When the defendants bring a validity counterclaim before local or regional courts, the judges have the option to refer both actions to the Central Division with the agreement of the parties, refer the counterclaim for revocation to the Central Division and suspend or proceed with the infringement action or proceed with both actions, see Art. 33 para. 4 lit. a-c Unified Patent Court Agreement. For a discussion of the extent to which the establishment of the UPC can contribute to enhance judicial coherence, see Baldan and Van Zimmeren (2015).
} 
new system. ${ }^{71}$ This will give rise to the possibility of parallel, duplicate or inconsistent litigation and decisions. ${ }^{72}$ Litigation with European-wide effects remains a target rather than a reality. However, with the Central Division in London of the Court of First Instance having exclusive jurisdiction over revocation lawsuits, and the Court of Appeal leveling up eventual heterogeneous infringement and invalidity counterclaims before the local or regional divisions of the Contracting Member States, the UPC is expected to strengthen the harmonization of European patent litigation.

\section{Conclusion}

This paper investigates country-, technology- and industry-specificity of the European patent system. We develop a general model of patent disputes which proposes that both settlement and litigation are driven by patent quality. While at the settlement stage, the relative patent quality estimations of patent holder and infringer, respectively, determine whether a settlement is reached or not, at trial stage it is the judge's estimation of patent quality that decides the case. As a result, the model predicts that high quality patents will prevail in court, despite the selection effect at the settlement stage. We test the prediction of the model at the litigation stage using a dataset that covers patent litigation in Germany, France and the United Kingdom for the period between 2008 and 2012. We find evidence that the European patent system is heterogeneous across jurisdictions. The data provides some indication that the forum in which a patent case is brought matters more than the individual characteristics of litigated patent.

Albeit its numerous challenges, the UPC could be a real paradigm shift when it comes to heterogeneity in the European patent system, setting it on the path of a unitary patent system, both nominally and in practice. As evidenced by recent developments surrounding the UPC, this first step towards homogeneity will be countered by national resistance and institutional challenges. However, it is to be hoped that, with time, the idea of a single court for the enforcement of patents in Europe will be the norm. The state of innovation will certainly depend heavily on the capacity of Europe to form a united front.

Open Access This article is licensed under a Creative Commons Attribution 4.0 International License, which permits use, sharing, adaptation, distribution and reproduction in any medium or format, as long as

\footnotetext{
71 The European Court of Justice held that an agreement creating a unified patent litigation system including courts in countries outside the EU not compatible with the provisions of the Treaty on European Union and the Treaty on the Functioning of the European Union (European Court of Justice, Opinion 1/09, March 8, 2011). Henceforth, the States parties to the European Patent Convention but not to the EU were excluded. Three Member States also refused to join the new system (namely Spain, Poland and Croatia). Spain illustratively criticized the higher costs of enforcement in the UPC compared to Spanish courts, particularly for SME, and reasons of language.

72 A European patent validated in Spain, Germany and France would therefore be subject in parallel to the jurisdiction of a national court for its Spanish part and of the unified court for its German and French parts. This will require coordinating litigation for pan-European enforcement of patent rights, but also to a certain extent the continued potential for forum shopping.
} 
you give appropriate credit to the original author(s) and the source, provide a link to the Creative Commons licence, and indicate if changes were made. The images or other third party material in this article are included in the article's Creative Commons licence, unless indicated otherwise in a credit line to the material. If material is not included in the article's Creative Commons licence and your intended use is not permitted by statutory regulation or exceeds the permitted use, you will need to obtain permission directly from the copyright holder. To view a copy of this licence, visit http://creativecommons.org/licen ses/by/4.0/.

\section{Appendix}

\section{Technology coding}

We hand-coded the patents at dispute by following the classification developed by Allison et al. (2015) that distinguishes between mechanical, electronics, chemistry, biotechnology, software and optics patents as follows: ${ }^{73}$

(1) Mechanical. An invention in which the claims cover the use of mechanical parts, either solely or predominantly, sometimes combined with heat, hydraulics, pneumatics, or other power sources or power transfer techniques.

(2) Electronics. An invention in which the claims cover the use of traditional electronic circuitry or the storage or transmission of electric energy.

(3) Chemistry. An invention in which the claims cover chemical reactions, chemical compounds with specific elements and proportions, and chemical processes specifying specific elements and amounts or proportions. Closely related inventions such as those on purportedly novel metal alloys and nonmetallic composites are also included when the claims cover the specific components and proportions of such amalgams. This technology area includes "small-molecule" chemistry; DNA, antibodies, and other large molecules are included in the biotechnology category instead. Although many of the chemistry technology patents were assigned to the pharmaceutical industry category, they are also found in other industry categories such as semiconductors.

(4) Biotechnology. An invention in which the claims cover processes involving advanced genetic techniques intended to construct new microbial, plant, or animal strains; a product created from such a process; or the way such a process or product is used in biotechnology research. Although there are a number of different genetic-engineering techniques, for several reasons we decided not to disaggregate these techniques into separate technology areas.

(5) Software. An invention in which the claims cover data processing-the actual manipulation of data (and not merely transmission, receipt, or storage of data), regardless of whether the code carrying out such data processing is on a magnetic storage medium, embedded in a chip ("firmware"), or resident in flash memory.

${ }_{73}$ Allison et al. (2015). 
(6) Optics. An invention in which the claims cover the use of light waves or light energy. We also assigned certain patents in the "primary" software classification to one of that technology's subsets, namely, software business methods. As we defined it, the software business method category includes software patents that cover models, methods, and techniques for conducting business transactions. Business-method patents are notoriously difficult to define, with possible definitions varying greatly in scope.

\section{Industry coding}

Similarily, we utilized classification developed by Allison et al. (2015) to distinguish patents by industry of use: ${ }^{74}$

(1) Computer and Other Electronics. This industry encompasses inventions of all kinds that purport to advance the state of the art in computing or computer device manufacturing, or to enhance users' experiences in employing computing technology. The category includes software and computer hardware inventions that seek to serve the aforementioned purposes. Also included are inventions predominated by the use of traditional electronic circuitry when those inventions purport to advance the art in that technology or enhance users' experiences in employing electronics technology. In contrast with our prior studies, here we combine the computer and traditional electronics industries because we find fewer and fewer patents covering traditional electronics without also including significant data processing elements. Traditional electronics inventions without data processing elements do continue to exist, but their frequency and importance is rapidly declining-the industries clearly have been merging for quite some time.

(2) Semiconductor. The semiconductor industry category includes inventions of any kind intended to advance the state of the art in researching, designing, or fabricating semiconductor chips. Technologies employed in semiconductor industry inventions may include software, chemistry, optics, and mechanical.

(3) Pharmaceutical. The pharmaceutical industry category includes patents on drugs for treating diseases or other abnormal conditions in humans or animals, as well as processes for producing or using such drugs. The technologies found in pharmaceutical industry inventions are overwhelmingly chemistry or biotechnology.

(4) Medical Devices, Methods, \& Other Medical. This industry category includes , non-biotechnology inventions of any kind used for research on, or for the diagnosis or treatment of, diseases or other abnormal conditions in humans or animals. Patents on processes and products for pharmaceutical purposes are not included in this category. All of the different technology fields are represented in the medical industry category.

74 Allison et al. (2015). 
(5) Biotechnology. This category includes those inventions that are in the biotechnology technology category that do not relate to the production of pharmaceutical compositions or medical diagnostics or treatment, but that instead purport to advance the science of biotechnology itself.

(6) Communications. The communications industry category includes inventions of all kinds intended to advance the state of the art in communications. Technologies represented in the communications industry include software, electronics, optics, and mechanics.

(7) Transportation. This category includes patents on any type of invention related to the production of automobiles or vehicles of any other kind intended for transporting people or cargo, and inventions related to the provision of transportation services. Several different technology areas are represented in this industry category.

(8) Construction. The construction industry category includes inventions of all kinds related to the erection or maintenance of structures, or to excavation.

(9) Energy. This category includes inventions of any kind associated with power generation, transportation, or consumption.

(10) Goods \& Services for Industrial \& Business Uses. This category includes patents on products and services of all kinds intended for industrial and business purposes-i.e. goods and services for wholesale uses that are not in another, more specific category. Many software-implemented business method inventions are included in this category.

(11) Goods \& Services for Consumer Uses. This category includes patents on products and services of all kinds intended for personal consumer purposes-i.e. goods and services for retail uses that are not in another, more specific category. Many software-implemented business method inventions are included in this category.

\section{Litigation outcomes by technology and industry}

See Tables 5, 6, 7 and 8 .

Table 5 Infringement by technology

\begin{tabular}{|c|c|c|c|c|c|c|}
\hline \multirow[t]{3}{*}{ Technology } & \multicolumn{6}{|c|}{ Infringement by technology } \\
\hline & \multicolumn{2}{|l|}{ Germany } & \multicolumn{2}{|l|}{ France } & \multicolumn{2}{|l|}{ UK } \\
\hline & Frequency & Win $\%$ & Frequency & Win $\%$ & Frequency & Win \% \\
\hline Mechanical & 325 & 59.69 & 152 & 54.11 & 32 & 59.38 \\
\hline Electronics & 86 & 59.30 & 36 & 66.67 & 10 & 80.00 \\
\hline Chemistry & 42 & 61.90 & 20 & 47.37 & 11 & 54.55 \\
\hline Software & 68 & 61.76 & - & - & 5 & 100.0 \\
\hline Optics & 34 & 73.53 & 3 & 66.67 & 1 & 0.0 \\
\hline Biotechnology & 10 & 80.00 & 1 & 0.0 & 2 & 0.0 \\
\hline Total & 565 & 61.24 & 205 & 55.61 & 61 & 63.93 \\
\hline
\end{tabular}


Table 6 Invalidity by technology

\begin{tabular}{|c|c|c|c|c|c|c|}
\hline \multirow[t]{3}{*}{ Technology } & \multicolumn{6}{|c|}{ Invalidity by technology } \\
\hline & \multicolumn{2}{|l|}{ Germany } & \multicolumn{2}{|l|}{ France } & \multicolumn{2}{|l|}{ UK } \\
\hline & Frequency & Win $\%$ & Frequency & Win $\%$ & Frequency & Win $\%$ \\
\hline Mechanical & 63 & 58.73 & 165 & 55.15 & 32 & 56.25 \\
\hline Electronics & 28 & 60.71 & 29 & 62.07 & 10 & 0.0 \\
\hline Chemistry & 10 & 20.0 & 22 & 45.45 & 10 & 40.00 \\
\hline Software & 23 & 30.43 & 4 & 0.0 & 5 & 0.0 \\
\hline Optics & 13 & 30.77 & 5 & 60.0 & 1 & 0.0 \\
\hline Biotechnology & 3 & 66.7 & - & - & 2 & 0 \\
\hline Total & 140 & 49.29 & 225 & 54.22 & 60 & 36.66 \\
\hline
\end{tabular}

Table 7 Overall win rate by industry

\begin{tabular}{|c|c|c|c|c|c|c|}
\hline \multirow[t]{3}{*}{ Technology } & \multicolumn{6}{|c|}{ Overall win rate by industry } \\
\hline & \multicolumn{2}{|l|}{ Germany } & \multicolumn{2}{|l|}{ France } & \multicolumn{2}{|l|}{ UK } \\
\hline & Frequency & Win $\%$ & Frequency & Win $\%$ & Frequency & Win $\%$ \\
\hline Goods \& services for industrial uses & 161 & 55.90 & 81 & 28.4 & 17 & 29.41 \\
\hline Construction & 74 & 40.54 & 58 & 22.41 & 2 & 100.0 \\
\hline Transportation & 56 & 58.93 & 55 & 43.64 & 7 & 42.86 \\
\hline Goods \& services for consumer uses & 56 & 57.14 & 48 & 54.2 & 3 & 33.30 \\
\hline Medical devices, methods \& medical & 47 & 59.57 & 15 & 13.3 & 9 & 11.10 \\
\hline Computer and other electronics & 55 & 52.73 & 14 & 42.86 & 2 & 0.0 \\
\hline Communications & 61 & 45.90 & 13 & 92.31 & 12 & 8.3 \\
\hline Pharmaceuticals & 16 & 37.50 & 15 & 33.3 & 9 & 22.2 \\
\hline Energy & 18 & 77.78 & 4 & 25.0 & 2 & 0 \\
\hline Semiconductor & 9 & 44.4 & 1 & 0.0 & - & - \\
\hline Biotechnology & 12 & 83.3 & - & - & - & - \\
\hline Total & 565 & 53.81 & 304 & 36.84 & 61 & 24.59 \\
\hline
\end{tabular}

\section{Patent quality results}

To arrive at the Patent Quality Index we performed a principle-components factor analysis, using varimax rotations. We then run a Horn's parallel analysis, a method to determine the number of factors to retain from the factor analysis. We kept those factors whose average eigenvalue were greater than the average eigenvalues (and higher than 1, according to the Kaiser criterion). The two factors explained for $56.6 \%$ of the variance. The factor loading matrix for this final solution is presented in Table 9. 
Table 8 Invalidity by industry

\begin{tabular}{|c|c|c|c|c|c|c|}
\hline \multirow[t]{3}{*}{ Technology } & \multicolumn{6}{|c|}{ Invalidity win rate by industry } \\
\hline & \multicolumn{2}{|l|}{ Germany } & \multicolumn{2}{|l|}{ France } & \multicolumn{2}{|l|}{ UK } \\
\hline & Frequency & Win $\%$ & Frequency & Win $\%$ & Frequency & Win $\%$ \\
\hline Goods \& services for industrial uses & 39 & 58.97 & 64 & 51.56 & 17 & 35.29 \\
\hline Construction & 13 & 61.54 & 44 & 45.45 & 2 & 100.0 \\
\hline Transportation & 7 & 57.14 & 39 & 61.54 & 7 & 71.43 \\
\hline Goods \& services for consumer uses & 11 & 36.36 & 39 & 71.79 & 3 & 33.3 \\
\hline Medical devices, methods \& medical & 17 & 41.18 & 11 & 27.27 & 9 & 66.67 \\
\hline Computer and other electronics & 13 & 53.85 & 12 & 58.33 & 2 & 0.0 \\
\hline Communications & 26 & 34.62 & 5 & 80.0 & 12 & 0.0 \\
\hline Pharmaceuticals & 3 & 0.0 & 8 & 25.0 & 8 & 28.57 \\
\hline Energy & 3 & 66.67 & 2 & 50.0 & 2 & 0 \\
\hline Semiconductor & 5 & 60.0 & 1 & 0.0 & - & - \\
\hline Biotechnology & 3 & 66.67 & - & - & - & - \\
\hline Total & 140 & 49.29 & 225 & 54.22 & 60 & 36.67 \\
\hline
\end{tabular}

Table 9 Factor loadings

\begin{tabular}{ll}
\hline Variable & Factor loading \\
\hline Number of IPC & 0.75 \\
Number of claims & 0.75 \\
\hline
\end{tabular}

Figures 12 and 13 represent the average patent quality by technology and by industry, with the error lower and upper bound.

\section{Predicted probabilities}

See Figs. 14 and 15.

\section{Coding book}

This Section reports the procedure followed in the collection and coding of the patent decisions.

(1) Type of cases. We collected all substantive decisions by courts on patent infringement and subsequent validity counterclaims. That is, revocation decisions were excluded, unless counted as counterclaim (see 'Bifurcation' for Germany). When a patent infringement decision was raised as a counterclaim to a 


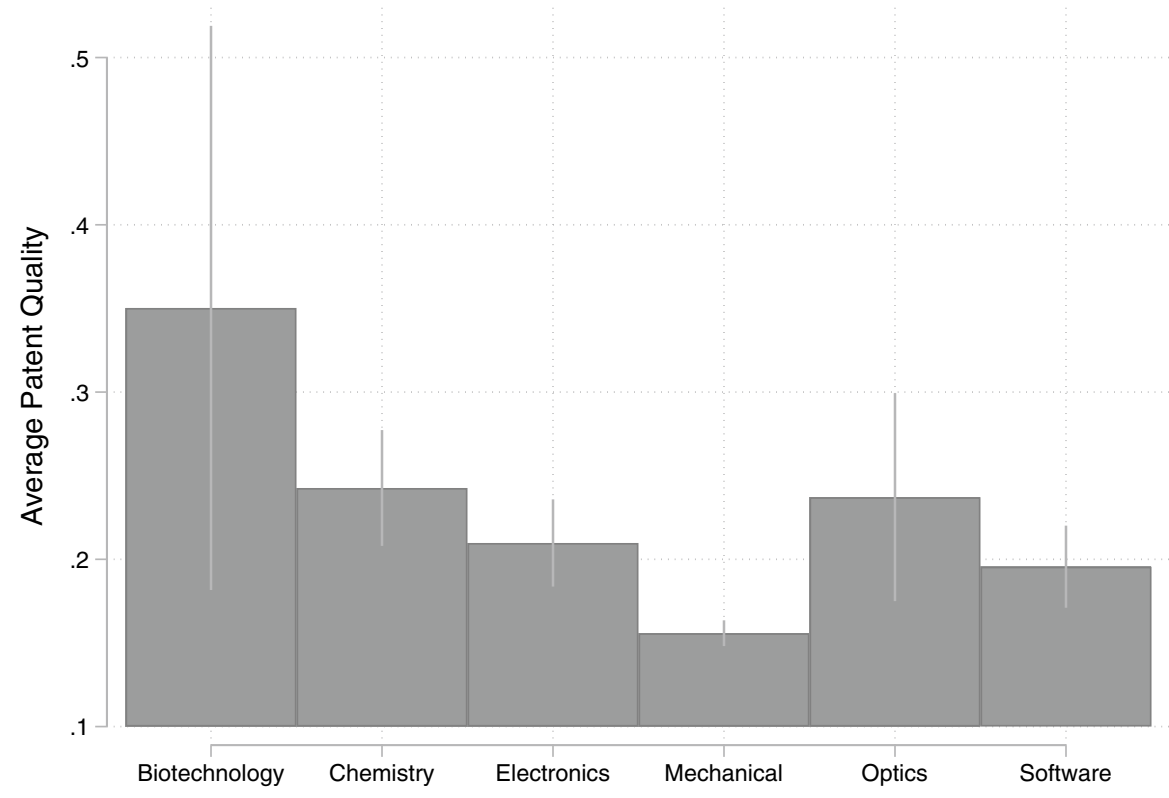

Fig. 12 Average patent quality, by technology

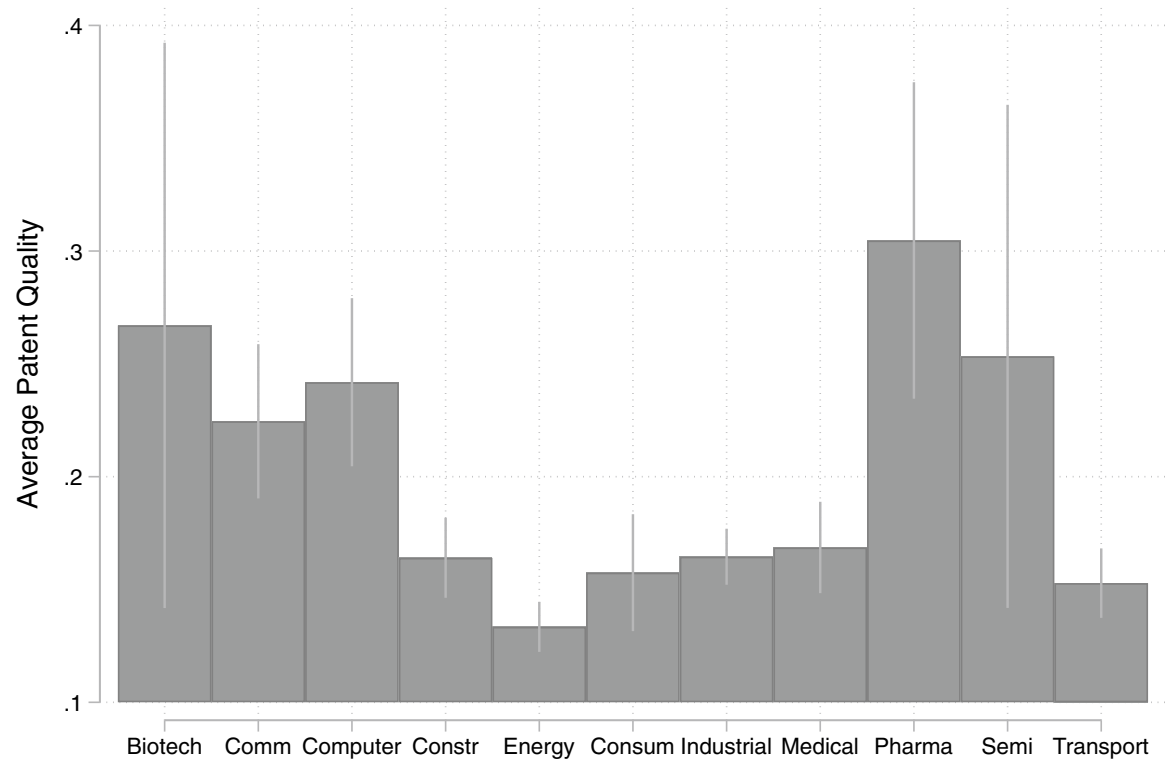

Fig. 13 Average patent quality, by Industry

revocation action, it was excluded. We excluded injunctions, procedural decisions, and non-infringement decisions. 


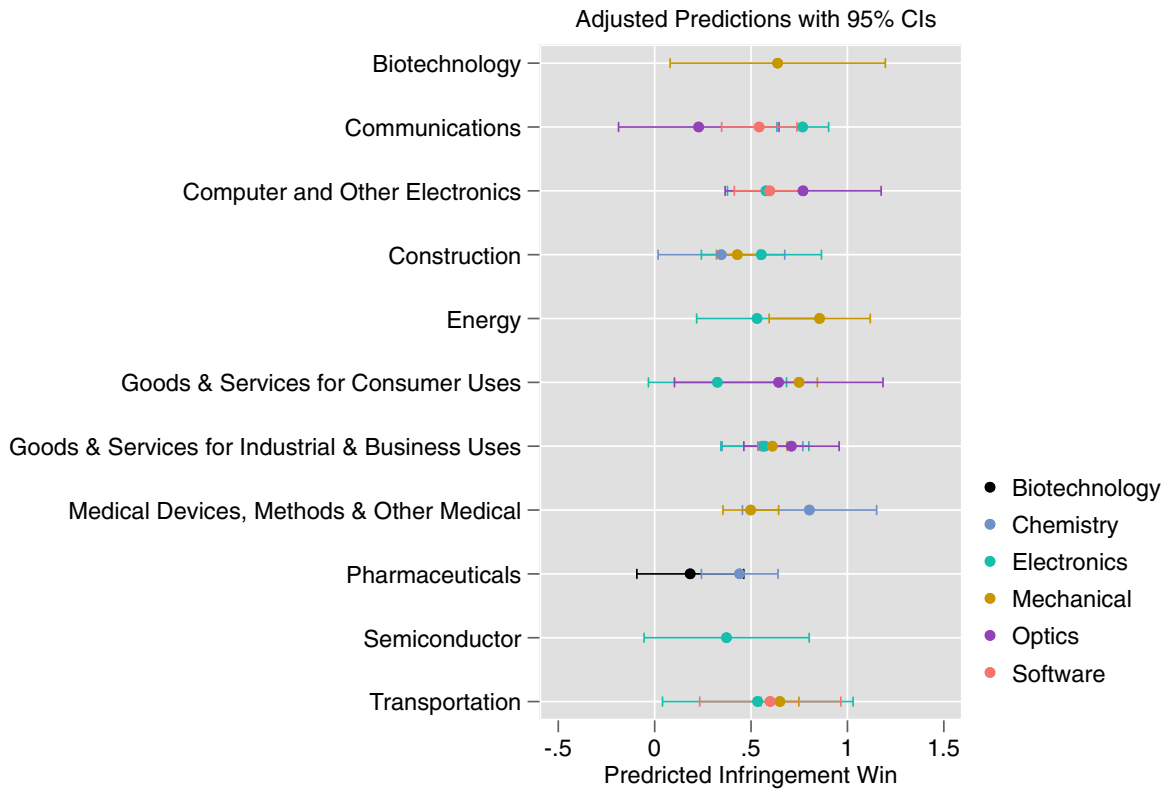

Fig. 14 Predicted probabilities infringement technology industry interaction

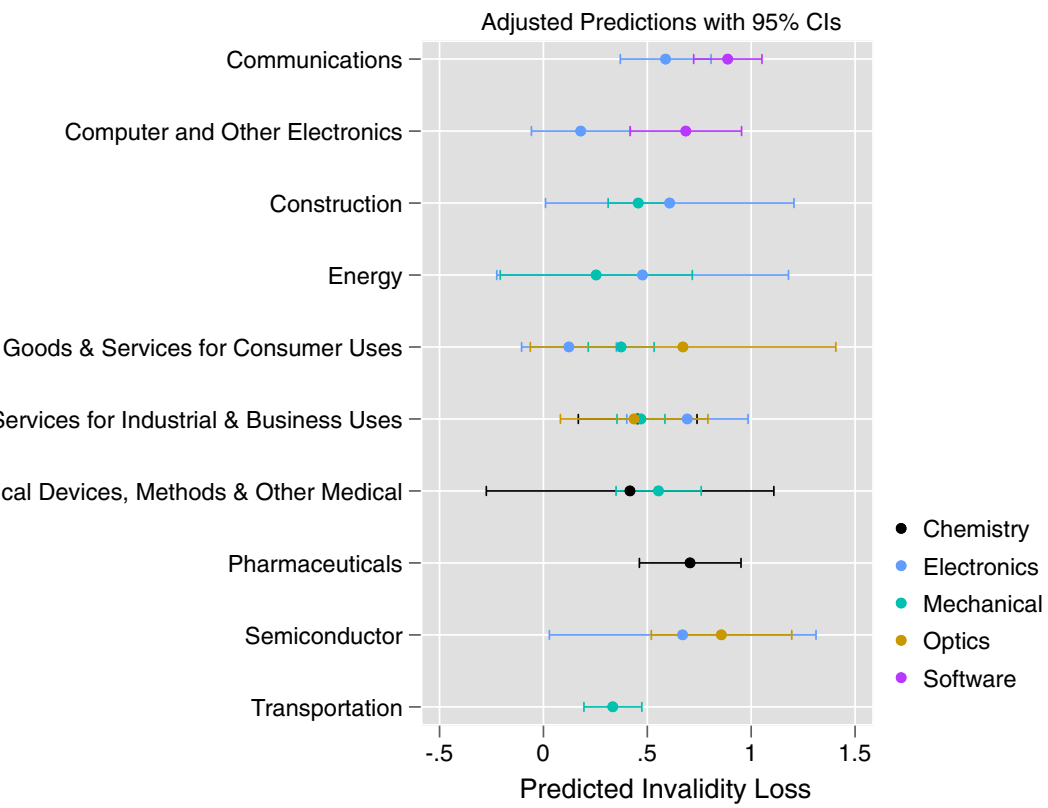

Fig. 15 Predicted probabilities invalidity technology industry interaction 
(2) Bifurcation. Because of the differences in patent system, infringement and revocation had to be treated differently in Germany. For disputes before German courts, we joined patent infringement disputes (before the regional courts) and invalidation disputes (before the Bundespatentgericht). A patent infringement dispute followed by an invalidity dispute over the same patent was considered equivalent to a counterclaim in France or in the UK. To be counted as such, the decision had to be rendered between the same parties, over the same patent and over a timespan of 2 years after the (first or last) infringement decision. If the parties were anonymised, we assumed that they were identical if the decision was rendered within a timespan of two years. In fact, we confirmed for 120 of 123 invalidity cases in Düsseldorf that it was one of the alleged infringer that challenged the validity of the (arguably) infringing patent. Inversely, if an invalidation decision was rendered before the infringement decision, the case was excluded and considered as revocation with infringement counterclaim. The latter cases are rare, with estimations that $90 \%$ of all revocation actions are filed in response to an infringement action. ${ }^{75}$

(3) Timespan. The first instance decision had to be rendered between January 1, 2008 and December 31, 2012 to be counted as relevant. The first substantive decision was determinant, that is previous procedural decisions would not affect this count. The search was first conducted in 2015 with a complete second coding run in 2017. Litigation cases in Mannheim and Munich were coded in 2018.

(4) Outcome. The outcomes are reported from the standpoint of the patent holder. An overall 'win' was reported if the patent holder could enforce its infringement claim before the courts, i.e. at least one of the claims was found to be infringed and that claim was, if challenged, upheld as valid. For infringement specifically, a 'win' was reported if at least one claim was found to be infringed, not matter its validity. For validity specifically, a 'win' was reported if the claim in dispute, or in case of several claims at stake, one of the claims that was found to be infringed was found valid. Assume the following example to clarify the coding: At decision stage, patent claim 1 was found to be infringed and valid, while claim 2 was declared not infringed and invalid; the overall outcome would be coded as a 'win', the infringement outcome as a 'win' and the validity outcome as a 'win'.

A further difficulty in outcome coding is the presence of partial invalidity decisions in Germany ('Teilnichtigkeit'). For such decisions, since infringement and validity proceedings are separated, it is unclear whether the infringing act falls within the amended claim. In our main specification, if the amended claim is upheld, we assumed that a violation was given and recorded an overall 'win'. In a further specification, we excluded those instances, which did not affect out results. ${ }^{76}$

\footnotetext{
${ }^{75}$ Hees, A. and Braitmyer, S.-E. Verfahrensrecht in Patentsache, Carl Heymanns Verlag (2010).

${ }^{76}$ With an overall win rate at $53.11 \%$ compared to $53.44 \%$ across all technologies, and within $1 \%$ difference by technology.
} 


\section{Relation with the Priest-Klein hypothesis}

In relating our model to Priest and Klein (1984), we rely on the Priest-Klein model formalization of Lee and Klerman (2016). Like our model, Priest and Klein is a divergent expectation model, where the litigation condition depends on the relative estimate of the plaintiff's versus the defendant's success probability. In the Priest-Klein model, divergent expectations result from an "error" which can result from a number of factors, such as errors in the interpretation of the law, errors in interpreting the respective case factual merits, or incomplete information concerning either. The equivalent to the errors term under Priest-Klein, resulting from noisy signals, in our model is the patent definiteness factor, which we consider to be the noise factor that captures residual uncertainty for both parties.

Similar to our model with our assumptions, settlement in the Priest and Klein setting will occur where the plaintiff's estimate of the success probability is below that of the defendant. However, unlike the Priest and Klein model, which presumes that both parties of a litigation base their estimates around a common judicial fault standard, our model assumes that parties make case assessments with regards to patent quality, without taking into account a common judicial standard. Only in the second stage, when the parties have already decided to proceed to court, does the judicial standard come into play, through the judge's own assessment of patent quality. The reasoning behind this is that in the specific institutional setting which forms the subject of our theoretical and empirical analysis, namely the European patent court system, there is no common judicial standard, as parties can litigate before multiple courts.

Under Priest and Klein, in the limit, where the standard deviation of the estimation error term approach zero, no cases will go to trial as the parties will have certainty over litigation outcome and will always settle. In turn, if the standard deviation of the estimation error term rises there will be fewer settlements and more cases proceeding to trial. This is in line with our model of the parties estimate of patent quality, which diverge depending on the definiteness factor: the less definite the patents get, the more litigation is to expected.

Under Priest-Klein, the hypothesis states that in the limit proportion of victories will approach 50 percent exactly as the estimation error diminishes and the litigation rates decline. In contrast to this, we only introduce the judicial standard in a second step, namely when both parties have already decided to proceed to trial. If we assume that the judge's error term follows the same distribution as that of the parties, a similar result as under Priest-Klein is to be expected. However, if one assumes, that the judge follows a fully independent distribution from that of plaintiff and claimant, the Priest-Klein hypothesis does not hold true and we are to expect a divergence in outcomes. Given the heterogeneity in legal standards across the European patent system, we assume that the latter is the case. With the advent of the UPC, however, we can expect a gradual shift towards a more common distribution. 


\section{References}

Alesina, A., Ignazio, A., \& Ludger, S. (2005). What does the European Union do? Public Choice, 123, 275-319.

Allison, J. R., Lemley, M. A., \& Schwartz, D. (2015). Our divided patent system. University of Chicago Law Review, 82, 1073.

Allison, J. R., Lemley, M. A., Moore, K. A., \& Trunkey, R. D. (2004). Valuable patents. Georgetown Law Journal, 92, 435.

Baldan, F., \& Van Zimmeren, E. (2015). The future role of the unified patent court in safeguarding coherence in the European patent system. Common Market Law Review, 52, 1529-1577.

Bender, G. (2000). Clash of the titans: The territoriality of patent law vs. the European Union. IDEA: The Journal of Law and Technology, 40, 49-82.

Bessen, J., \& Michael, M. (2007). The private costs of patent litigation. Boston University School of Law Working Paper 07-08.

Brandi-Dohrn, M. (2012). Some critical observations on competence and procedure of the unified patent court. International Review of Intellectual Property and Competition Law, 43, 372-389.

Choi, S. J., \& Gulati, M. G. (2008). Bias in judicial citations: A window into the behavior of judges? Journal of Legal Studies, 37, 87-129.

Clermont, K. (2009). Litigation realities redux. Notre Dame Law Review, 84, 1951-1956.

Clermont, K., \& Eisenberg, T. (2002). Litigation realities. Cornell Law Review, 119, 137-40.

Cooter, R., \& Ulen, T. (2016). Law \& economics. Berkeley: Berkeley Law Books.

Cremers, K. (2004). Determinants of patent litigation in Germany. ZEW discussion paper, 04-72.

Cremers, K., Ernicke, M., Gaessler, F., Harhoff, D., Helmers, C., McDonagh, L., et al. (2016). Patent litigation in Europe. European Journal of Law and Economics, 44, 1-44.

Cremers, K., Gaessler, F., Harhoff, D., Helmers, C., \& Lefouili, Y. (2016). Invalid but infringed? An analysis of the bifurcated patent litigation system. Journal of Economic Behavior \& Organization, 131, 218-242.

Cremers, K., \& Schliessler, P. (2015). Patent litigation settlement in germany: Why parties settle during trial. European Journal of Law and Economics, 40(2), 185-208.

Di Cataldo, V. (2002). From the European patent to a community patent. Columbia Journal of European Law, 8, 19-36.

Duffy, J. F. (2002). Harmony and diversity in global patent law. Berkeley Technology Law Journal, $17,685-726$.

Dumont, B. (2014). The link between damages and patent value in the French judicial system. Working paper.

Ellis, T. (1999). Distortion of patent economics by litigation costs. CASRIP Publication Series: Streamlining Int'l Intellectual, 5, 22-23.

Elmer, M., \& Lewis, S. (2014). Where to win: Patent-friendly courts revealed. Managing Intellectual Property October 2010.

Furata, Y. (1995). International parallel litigation: Disposition of duplicative civil proceedingsin the United States and Japan. Pacific Rim Law \& Policy, 1, 1-58.

Gambardella, A., Harhoff, D., \& Verspagen, B. (2008). The value of European patents. European Management Review, 5, 69-84.

Gawel, C. R. (2006). Patent protection as a key driver for pharmaceutical innovation. Pharmaceuticals Policy and Law, 18(1-4), 45-53.

Graham, S. J., \& Van Zeebroeck, N. (2014). Comparing patent litigation across Europe: A first look. Stanford Technology Law Review, 17, 655-708.

Hall, B. H., Thoma, G., \& Torrisi, S. (2007). The market value of patents and R\&D: Evidence from European firms. NBER working paper 13426.

Harhoff, D. (2009). Economic cost-benefit analysis of a unified and integrated European patent litigation system. Final report, tender no. Markt/2008/06/D.

Harhoff, D., Scherer, F., \& Vogel, K. (1999). Citation frequency and the value of patented innovation. Review of Economics and Statistics, 81, 511-515.

Hatter, J. P. (1995). The doctrine of equivalents in patent litigation: An analysis of the epilady. Indiana International \& Comparative Law Review, 5, 461-494.

Hees, A., \& Braitmayer, S.-E. (2010). Verfahrensrecht in Patentsachen. Cologne: Carl Heymanns Verlag. 
Helmers, C., \& McDonagh, L. (2013). Patent litigation in the UK: An empirical survey 2000-2008. Journal of Intellectual Property \& Practice, 8, 846-861.

Impact of the Unitary Patent Protection and the Unified Patent Court in the Nordic-Baltic Region. (2014, October). Ministry of Justice of Sweden.

Johnson, A., \& Maunder, L. (2017). Challenging the UPC opt-out-How exactly will it work?. London: Bristows.

Kessler, D., Meites, T., \& Miller, G. P. (1996). Explaining deviations from the fifty-percent rule: A multimodal approach to the selection of cases for litigation. The Journal of Legal Studies, 25(1), $233-59$.

Keukenschrijver, A. (2011). Patentnichtigkeitsverfahren. Cologne: Heymann.

Knoll, B., Baumann, M., \& Riedel, N. (2014). The global effects of $R \& D$ tax incentives: Evidence from micro-data. Beiträge zur Jahrestagung des Vereins für Socialpolitik 2014: Evidenzbasierte Wirtschaftspolitik - Session: Taxation II.

Kox, H., Lejour, A., \& Montizaan, R. (2004). The free movement of services within the EU. C.P.B. document.

Laddie, H. (2009). Kirin Amgen-The end of equivalents in England? Eppur Si Muove - Support the Resolution and Day That in Any Case British Law Already Conforms. IIC, 3-38.

Lamping, M., \& Ullrich, H. (2018). The impact of Brexit on unitary patent protection and its court. Max Planck Institute for Innovation \& Competition Research Paper No., 18-20.

Lanjouw, J. O., \& Schankerman, M. (2004). Patent quality and research productivity: Measuring innovation with multiple indicators. The Economic Journal, 112, 441-465.

Larouche, P. (2013). Legal emulation between regulatory competition and comparative law. In P. Larouche \& P. Cserne (Eds.), National legal systems and globalization: New role, continuing relevance. Berlin: Springer.

Lee, Y. H. A., \& Klerman, D. (2016). The Priest-Klein hypotheses: Proofs and generality. International Review of Law and Economics, 48, 59-76. https://doi.org/10.1016/j.irle.2016.06.002.

Lemley, M. A. (2001). Rational ignorance at the patent office. Northwestern University Law Review, $95,1495$.

Lerner, J. (1994). The importance of patent scope: An empirical analysis. The Rand Journal of Economics, 25(2), 319-333.

Luginbuehl, S. (2011). European patent law-Towards a uniform interpretation. Cheltenham: Edward Elgar.

Mahne, K. P. (2012). A unitary patent and unified patent court for the European Union: An analysis of Europe's long standing attempt to create a supranational patent system. Journal of the Patent and Trademark Office Society, 94, 162-191.

Mann, R., \& Underweiser, M. (2012). A new look at patent quality: Relating patent prosecution to validity. Journal of Empirical Legal Studies, 9(1), 1-32.

Mejer, M., \& van Pottelsberghe de la Potterie, B. (2009). Economic incongruities in the European patent system. ECARES working paper 2009-003.

Moore, K. A. (2005). Worthless patents. Berkeley Technology Law Journal, 20, 1521.

Moss, G., Jones, M. A., \& Lundie-Smith, R. (2010). Just how 'anti-patent' are the UK courts? Journal of Intellectual Property Law \& Practice, 5(3), 148-157.

Murashige, K. H. (1994). Harmonization of patent laws. Houston Journal of International Law, 16, 591-614.

Nard, C. A., \& Duffy, J. F. (2007). Rethinking patent law's uniformity principle. Northwestern University Law Review, 101(4), 1619-1676.

OECD. (2005). A framework for biotechnology statistics.

Ohly, A., \& Streinz, R. (2017). Can the UK stay in the UPC system after Brexit? Journal of Intellectual Property Law \& Practice, 12(3), 245-258.

Parker, M. (2012). Giving teeth to European patent reform, overcoming recent legal challenges. Emory International Law Review, 26, 1079-1110.

Pinckney, R. (2015). Understanding the transitional provisions of the agreement on the unified patent court. European Intellectual Property Review, 37(5), 268-277.

Priest, G. L., \& Klein, B. (1984). The selection of disputes for litigation. The Journal of Legal Studies, 13(1), 1-56.

Romandini, R., \& Klicznik, A. (2013). The territoriality principle and transnational use of patented inventions-The wider reach of a unitary patent and the role of the CJEU. International Review of Intellectual Property and Competition Law, 44(5), 524-540. 
Rubinfeld, D. L., \& Scotchmer, S. (1993). Contingent fees for attorneys: An economic analysis. The Rand Journal of Economics, 24(3), 343-356.

Sterckx, S., \& Cockbain, J. (2009). The patentability of computer programs in europe: An improved interpretation of articles 52(2) and (3) of the european patent convention. The Journal of World Intellectual Property, 13, 366-402. https://doi.org/10.1111/j.1747-1796.2009.00390.x.

Tilmann, W. (2006). The harmonisation of invalidity and scope of protection practice of the national courts of EPC member states. ICC, 37, 62-74.

Towards an enhanced patent litigation system and a community patent-How to take discussions further. (2007). The European Council.

Triet, G., \& Santarelli, L. (2000). Propriété industrielle, le coût des litiges, Etude comparée entre la France, l'Allemagne, l'Angleterre, les États-Unis, l'Espagne et les Pays-Bas. Ministère de l'Economie, des Finances et de l'Industrie.

Véron, P. (2010). Le Contentieux des Brevets d'Invention en France. Etude Statistique, 2000-2010.

Webbink, M. H. (2005). A new paradigm for intellectual property rights in software. Duke Law \& Technology Review, 4, 1-15.

Xenos, D. (2013). The European unified patent court: Assessment and implications of the federalisation of the patent system in Europe. SCRIPTed: A Journal of Law, Technology and Society, $10(2), 246-277$.

Yarsky, J. (2017). Hastening harmonization in European Union patent law through a preliminary reference power. Boston College International and Comparative Law Review, 40, 167-193.

Publisher's Note Springer Nature remains neutral with regard to jurisdictional claims in published maps and institutional affiliations.

\section{Affiliations}

\section{Raphael Zingg ${ }^{1,2} \cdot$ Erasmus Elsner $^{2}$}

Raphael Zingg

rzingg@ethz.ch

Erasmus Elsner

elsnere@ethz.ch

1 Institute for Advanced Study, Waseda University, Tokyo 169-8050, Japan

2 Center for Law and Economic, ETH Zurich, 8092 Zurich, Switzerland 